\title{
LEGITIMATION UND DELEGITIMIERUNG VON FEHDEN IN JURISTISCHEN UND THEOLOGISCHEN DISKURSEN DES SPÄTMITTELALTERS
}

Frieden zu schaffen darf als zentrale Aufgabe mittelalterlicher Herrschaft betrachtet werden. Im römisch-deutschen Reich stellte sich dieses Problem bekanntlich nicht nur in Bezug auf äußere Feinde, von denen das Reich zwischen der Mitte des 10. Jahrhunderts und dem ersten Drittel des 15. Jahrhunderts kaum je bedroht war ${ }^{1}$, sondern in Bezug auf die Befriedung im Innern. Denn im Gegensatz zu den westeuropäischen Monarchien gelang es im Reich nicht, die adlige Eigenmacht, die sich in Fehden äußerte, faktisch zu unterbinden oder wenigstens theoretisch zu kriminalisieren. Gleichwohl ziehen sich die Bestrebungen, dem Fehdewesen Regeln zu geben, durch das Hoch- und Spätmittelalter; vereinzelt lassen sich im 14. Jahrhundert und vermehrt im 15. Jahrhundert Bemühungen aufzeigen, Fehdeführung ganz zu unterbinden. Doch war dies schwierig, denn die gewohnheitsrechtliche Verankerung der Fehde stand solchen Rechtsveränderungen im Wege.

Viele dieser Entwicklungen sind seit längerem Gegenstand der Forschung, dies gilt besonders für die hochmittelalterliche Gottes- und Landfriedensbewegung ${ }^{2}$. Der hier gebotene Beitrag setzt daher andere Akzente. In einem

1 Vgl. dazu Hillay ZmorA, Values and Violence. The Morals of Feuding in Late Medieval Germany, in: Jeppe Büchert Netterstrøm, Bjørn Poulsen (Hg.), Feud in Medieval and Early Modern Europe, Aarhus 2007, S. 147-160, hier S. 149.

2 An jüngeren Publikationen zum Hochmittelalter seien genannt: Elmar WADLE, Landfrieden, Strafe, Recht. Zwölf Studien zum Mittelalter, Berlin 2001 (Schriften zur Europäischen Rechts- und Verfassungsgeschichte, 37); Arno BuschmanN, Elmar WAdLE (Hg.), Landfrieden. Anspruch und Wirklichkeit, Paderborn u.a. 2002 (Rechtsund Staatswissenschaftliche Veröffentlichungen der Görres-Gesellschaft, Neue Folge, 98); Elmar WADlE, Die Wahrung des Landfriedens als Aufgabe des Herrschers: Gedanken zur Regentschaft Friedrich Barbarossas und Friedrichs II., in: Gerhard Dilcher, Diego QuAglioni (Hg.), Gli inizi del diritto pubblico, Bd. 2: Da Federico I a Federico II./Die Anfänge des öffentlichen Rechts. Von Friedrich Barbarossa zu Friedrich II. (Annali dell'Istituto storico italo-germanico in Trento. Contributi 21/ Jahrbuch des italienisch-deutschen historischen Instituts in Trient, Beiträge 21), Bologna, Berlin 2008, S. 37-66; Thomas GERGEN, Pratique juridique de la paix et trêve de Dieu à partir du concile de Charroux, Frankfurt a.M. 2004 (Rechtshistorische Reihe, 285); Hans-Werner GoETZ, Pacem et iustitiam facere. Zum Rechtsverständnis in den Gottes- und Landfrieden, in: Tiziana J. Chiusi, Thomas Gergen, Heike Jung (Hg.), Das Recht und seine historischen Grundlagen. Festschrift für Elmar Wadle zum 70. Geburtstag, Berlin 2008 (Schriften zur Rechtsgeschichte, 139), S. 283-295. Zum 
ersten Schritt soll belegt werden, dass ein Adliger, der im römisch-deutschen Reich des Spätmittelalters Fehde führte, sich nicht nur auf soziale Normen berufen konnte, sondern dass auch Rechtsquellen die Zulässigkeit von Fehde voraussetzen oder sogar thematisieren. Dieser Argumentationsschritt scheint mir nötig, da die Annahme, Recht und Gewalt müssten sich ausschließen, heute so weit verbreitet ist, dass die umgekehrte Annahme einer Zulässigkeit adliger Eigenmacht in jüngerer Zeit unter Ideologieverdacht geraten ist ${ }^{3}$.

Nur ganz kurz werden in einem zweiten Schritt die landesherrlichen und die königlichen Bestrebungen gestreift, Fehden einzudämmen. Ebenfalls nur knapp wird an die Rolle des gelehrten, insbesondere des römischen Rechts erinnert, das einen innovativen Beitrag zum Diskurs über die Fehde- und Friedensproblematik lieferte und über dessen Einfluss andere Forscher, insbesondere Alfred Vanderpol ${ }^{4}$, Maurice Keen 5 , Ernst-Dieter Hehl' ${ }^{6}$, Eberhard Isenmann ${ }^{7}$, Helmut G. Walther ${ }^{8}$, Karl-Heinz Ziegler ${ }^{9}$ und Markus Schrödl ${ }^{10}$

Spätmittelalter vgl. Mattias G. FISCHER, Reichsreform und Ewiger Landfrieden. Über die Entwicklung des Fehderechts im 15. Jahrhundert bis zum absoluten Fehdeverbot von 1495, Aalen 2007 (Untersuchungen zur deutschen Staats- und Rechtsgeschichte, Neue Folge, 34). Eine Zusammenfassung des Forschungsstandes bieten Sabine ScHMOLINSKY, Klaus ARNOLD, Konfliktbewältigung. Kämpfen, Verhandeln und Frieden schließen im europäischen Mittelalter, in: Bernd Wegner (Hg.), Wie Kriege enden. Wege zum Frieden von der Antike bis zur Gegenwart, Paderborn u.a. 2002, S. 25-64 und Claudia GARNIER, Die Legitimierung von Gewalt durch die hoch- und spätmittelalterliche Friedensbewegung, in: Frühmittelalterliche Studien 42 (2008), S. 229-251. Der Artikel von Francisco Pavone, Gottesfrieden - Mechanismen zum Schutze der Schwachen im Hohen Mittelalter, in: Martin EcKOLDT (Hg.), Recht des Stärkeren - Recht des Schwächeren. Analysen und Perspektiven von Assistierenden des Rechtswissenschaftlichen Instituts der Universität Zürich, Zürich 2005, S. 87-109 lag mir nicht vor.

${ }^{3}$ Dies gilt bes. für die Einordnung der Ergebnisse Otto Brunners, vgl. Hans-Henning KoRtüM, »Wissenschaft im Doppelpaß«? Carl Schmitt, Otto Brunner und die Konstruktion der Fehde, in: Historische Zeitschrift 282 (2006), S. 585-617.

${ }^{4}$ Alfred M. VAnderpol, La doctrine scholastique du droit de guerre, Paris 1919.

${ }^{5}$ Maurice H. KeEn, The Laws of War in the Late Middle Ages, London 1965.

${ }^{6}$ Ernst-Dieter HeHL, Kirche und Krieg im 12. Jahrhundert, Stuttgart 1980; DeRS., Kirche, Krieg und Staatlichkeit im hohen Mittelalter, in: Werner RöSENER (Hg.), Staat und Krieg. Vom Mittelalter bis zur Moderne, Göttingen 2000 (Monographien zur Geschichte des Mittelalters, 19), S. 17-36; DERS., Krieg, Individualisierung und Staatlichkeit im ausgehenden 11. und im 12. Jahrhundert, in: Klaus Herbers (Hg.), Europa an der Wende vom 11. zum 12. Jahrhundert. Beiträge zu Ehren von Werner Goez, Stuttgart 2001, S. 117-133; Ders., Die Sorge für den Landfrieden als Fall des gerechten Krieges, in: Arno Buschmann, Elmar Wadle (Hg.), Landfrieden. Anspruch und Wirklichkeit, Paderborn u.a. 2002 (Rechts- und Staatswissenschaftliche Veröffentlichungen der Görres-Gesellschaft Neue Folge, 98), S. 55-72.

7 Eberhard IsEnManN, Reichsrecht und Reichsverfassung in den Konsilien reichsstädtischer Juristen (15.-17. Jahrhundert), in: Roman SchnuR (Hg.), Die Rolle der Juris- 
die maßgeblichen Forschungen vorgelegt haben. Ausführlicher soll drittens und letztens auf den Einfluss des Kirchenrechts und der Theologie eingegangen werden, wobei hier Autoren interessieren sollen, die aus dem Reich stammten und die dessen Lebenswirklichkeit reflektierten. Dabei soll besonders der geistlichen Vermittlungswege (z.B. der Bußsummen und der katechetischen Literatur) gedacht werden, auf denen kanonistische Positionen popularisiert wurden. Diese Vermittlungswege werden meines Erachtens in der deutschen Forschung unterschätzt, während etwa die englischsprachige Forschung die Stellungnahmen der Theologen zu Krieg und Frieden bereits für das Hochmittelalter in Relation zum Zeitgeschehen im eigenen Land gesetzt hat ${ }^{11}$. Gleichwohl wird man vermuten dürfen, dass durch die theologischen, zumal die praxisbezogenen katechetischen Schriften weitere Kreise erreicht und der Diskurs nachhaltiger bestimmt wurde als durch juristische Gutachten.

ten bei der Entstehung des modernen Staates, Berlin 1986, S. 545-628, hier S. 603613; Ders., Recht, Verfassung und Politik in Rechtsgutachten spätmittelalterlicher deutscher und italienischer Juristen, vornehmlich des 15. Jahrhunderts, in: Hartmut Boockmann u.a. (Hg.), Recht und Verfassung im Übergang vom Mittelalter zur Neuzeit, Teil 2, Göttingen 2001, S. 47-245, hier S. 128-134, 200-210.

${ }^{8}$ Helmut G. Walther, Die Rezeption Paduaner Rechtswissenschaft durch die Aufnahme Paduaner Konsilien in die Nürnberger Ratschlagbücher, in: Ingrid BAUMGÄRTNER (Hg.), Consilia im späten Mittelalter. Zum historischen Aussagewert einer Quellengattung, Sigmaringen 1995 (Studi. Schriftenreihe des Deutschen Studienzentrums in Venedig/Centro Tedesco di Studi Veneziani, 13), S. 207-224; WALTHER, Zur Rolle der Kanonistik in den Consilia der Nürnberger Ratsjuristen zum Reichsrecht, in: Uta-Renate Blumenthal, Kenneth Pennington, Atria A. Larson (Hg.), Proceedings of the Twelfth International Congress of Medieval Canon Law (Washington, D. C., 17 August 2004), Città del Vaticano 2008 (Monumenta iuris canonici Ser. C, 13), S. $447-488$.

9 Karl-Heinz ZIEGLER, Kriegsrechtliche Literatur im Spätmittelalter, in: Horst BRUNNER (Hg.), Der Krieg im Mittelalter und in der Frühen Neuzeit: Gründe, Begründungen, Bilder, Bräuche, Recht, Wiesbaden 1999 (Imagines medii aevi, 3), S. 57-71.

10 Markus SchröDL, Das Kriegsrecht des Gelehrten Rechts im 15. Jahrhundert. Die Lehren der Kanonistik und der Legistik über De bello, de represaliis et de duello, Hamburg 2006 (Rechtsgeschichtliche Studien, 14).

11 Vgl. John BALDwin, Masters, Princes and Merchants. The Social Views of Peter the Chanter and his Circle, 2 Bde., Princeton 1970, Bd. 1, S. 206-224; Paul R. HyAms, Rancor and Reconciliation in Medieval England, Ithaca 2003, S. 43-58; Richard W. KAEUPER, Holy Warriors. The Religious Ideology of Chivalry, Philadelphia 2009, S. 167-193. Die überaus verdienstvolle Studie von HeHL, Kirche und Krieg (wie Anm. 6) legt ihren Fokus auf den von hochmittelalterlichen Kanonisten in ganz Europa geführten Diskurs sowie auf dessen Kontextualisierung. 


\section{Die Definition der Fehde}

$\mathrm{Zu}$ Beginn meiner Ausführungen wird eine kurze Definition dessen vorangestellt, was unter dem Forschungsbegriff »Fehde« verstanden werden soll. Zunächst kann man in einem weiteren und Kulturen übergreifenden Sinn als Fehde einen »Zustand der Feindschaft zwischen zwei Parteien, die innerhalb derselben politischen Einheit oder Gesellschaft leben« bezeichnen, so der Rechtshistoriker Christoph Meyer ${ }^{12}$, sodann können die Folgen dieser Feindschaft als Fehde bezeichnet werden: Feud steht dann für regelgeleitete »customary vengeance ${ }^{13}$, wie sie in vielen europäischen und außereuropäischen Gesellschaften üblich war, ohne dort zwingend Rechtscharakter zu haben ${ }^{14}$. Nachdem die karolingerzeitlichen Anstrengungen, Fehden vermittels Sühnezwang zurückzudrängen, keine Fortsetzung mehr gefunden hatten ${ }^{15}$, etablierte sich Fehde, eher durch Rituale denn durch Rechtsnormen in Schranken gehalten ${ }^{16}$, im ostfränkisch-deutschen Reich als Mittel des Konfliktaustrags. Gottes- und Landfrieden zielten auf zeitweilige Suspension der Fehde und auf die Etablierung von Ausnahmen, etwa von geschützten Orten und Personen, sie zielten weniger auf Beseitigung der Gewalt denn auf ihre Begrenzung und die Regulierung von Schäden ${ }^{17}$. Für die »Anwendung oder

12 Christoph Meyer, Freunde, Feinde, Fehde: Funktionen kollektiver Gewalt im Frühmittelalter, in: Jürgen Weitzel (Hg.), Hoheitliches Strafen in der Spätantike und im frühen Mittelalter, Köln, Weimar, Wien 2002 (Konflikt, Verbrechen und Sanktion in der Geschichte Alteuropas. Symposien und Synthesen, 7), S. 211-266, hier S. 215.

13 Hyams, Rancor and Reconciliation (wie Anm. 11), S. 32.

14 Zur Problematik von Rache und Fehde vgl. zuletzt Paul Hyams, Susanna A. Throop (Hg.), Vengeance in the Middle Ages. Emotion, Religion and Feud, Farnham 2010; Belle S. Tuten, Tracey L. Billado (Hg.), Feud, Violence and Practice. Essays in Medieval Studies in Honor of Stephen D. WHITE, Farnham 2010; Daniel LoRD Smail, Kelly GiBSON (Hg.), Vengeance in Medieval Europe. A Reader, Toronto 2009. 15 Rudolf His, Das Strafrecht des deutschen Mittelalters, 2 Teile, Weimar 1920, ND Aalen 1964, Bd. 1, S. 263 und bes. Arnold AngEnEndT, Das Frühmittelalter. Die abendländische Christenheit von 400 bis 900, Stuttgart, Berlin, Köln ${ }^{3} 2001$, S. 357f.

16 Zum Regelwerk der hochmittelalterlichen Fehde vgl. zusammenfassend Gerd ALTHOFF, Regeln der Gewaltanwendung im Mittelalter, in: Rolf Peter SiEFERLE, Helga Breuninger (Hg.), Kulturen der Gewalt. Ritualisierung und Symbolisierung von Gewalt in der Geschichte, Frankfurt a.M. 1998, S. 157f.

17 Hans-Werner GoEtz, Kirchenschutz, Rechtswahrung und Reform. Zu den Zielen und zum Wesen der frühen Gottesfriedensbewegung in Frankreich, in: Francia 11 (1983), S. 193-239, bes. S. 223-225; DerS., Die Gottesfriedensbewegung im Licht neuerer Forschungen, in: Arno Buschmann, Elmar WAdLE, Landfrieden. Anspruch und Wirklichkeit, Paderborn u.a. 2002 (Rechts- und Staatswissenschaftliche Veröffentlichungen der Görres-Gesellschaft Neue Folge, 98), S. 31-54, hier S. 41; HansJoachim SCHMIDT, »Confoederatio pacis« und »militia Christi«. Über den Zusammenhang von Friedenssicherung, Schwurgenossenschaft und Judenfeindschaft im 11. 
Vermeidung von Gewalt« bedeutete dies im Umkehrschluss, dass beide Praktiken »in jedem Fall neu >ausgehandelt $\iota$, plausibilisiert und öffentlich dargestellt werden mussten $^{18}$.

Die fragile Beziehung zwischen Zulassung und Begrenzung von Eigengewalt bildete die Basis für jene Sondersituation des spätmittelalterlichen römisch-deutschen Reichs, in der spätestens seit der staufischen Landfriedensgesetzgebung mit dem Mainzer Landfrieden von 1235 als einem zentralen Referenzpunkt ${ }^{19}$ Fehde als "gewaltsame, aber regelgebundene rechtliche Selbsthilfe« akzeptiert wurde, welche beim Vorhandensein eines rechtlichen Grundes als »legitime Form des Konfliktaustrags « galt ${ }^{20}$. Arno Buschmann, ein weiterer Rechtshistoriker, definierte Fehde daher als »ein rechtlich anerkanntes und geregeltes Verfahren zur individuellen Rechtsdurchsetzung mit Waffengewalt « ${ }^{21}$. Zu guter Letzt sei noch auf die Ausführungen Hans Stadlers verwiesen, der im »Historischen Lexikon der Schweiz« eine deutsch- und eine französischsprachige Definition der Fehde bot, die in Anbetracht der relativ größeren Nähe der eidgenössischen Verhältnisse zu

und 12. Jahrhundert, in: Frank G. Hirschmann, Gerd Mentgen (Hg.), Campana pulsante convocati. Festschrift anlässlich der Emeritierung von Prof. Dr. Alfred Haverkamp, Trier 2005, S. 519-544, hier S. 523.

18 Christoph Auffarth, Heilsame Gewalt? Darstellung, Begründung und Kritik der Gewalt in den Kreuzzügen, in: Manuel Braun, Cornelia Herberichs (Hg.), Gewalt im Mittelalter. Realitäten - Imaginationen, München 2005, S. 251-272, hier S. 258.

19 Zum Mainzer Reichslandfrieden vgl. Arno Buschmann, Der Mainzer Reichslandfriede von 1235 - Anfänge einer geschriebenen Verfassung im Heiligen Römischen Reich, in: Juristische Schulung 31 (1991), S. 453-460; Mattias G. FISCHER, Über den Rechtscharakter der Fehde, in: Jost Hausmann, Thomas KRAuse, »Zur Erhaltung guter Ordnung«. Beiträge zur Geschichte von Recht und Justiz. Festschrift für Wolfgang Sellert zum 65. Geburtstag, Köln, Weimar, Wien 2000, S. 123-139, bes. S. 126134; Jörg MÜLleR, Der Mainzer Reichslandfrieden von 1235. Ein Beispiel zur Rezeption, in: Orazio Condorelli (Hg.), Panta rei. Studi dedicati a Manlio Bellomo, 5 Bde., Rom 2004, Bd. 4, S. 161-175.

20 Otto BRUNNER, Land und Herrschaft. Grundfragen der territorialen Verfassungsgeschichte Österreichs im Mittelalter, Darmstadt 1984 (ND der 5. Aufl., Wien 1965), S. 41-55, 73-86, 95-101; Christine REINLE, Fehdeführung und Fehdebekämpfung am Ende des Mittelalters, in: Joachim EMIG in Verbindung mit Wolfgang ENKE u.a. (Hg.), Altenburger Prinzenraub 1455. Strukturen und Mentalitäten eines spätmittelalterlichen Konflikts (Saxonia. Schriften des Vereins für sächsische Landesgeschichte, 9; Veröffentlichungen des Thüringischen Staatsarchivs Altenburg Sonderband), Beucha 2007, S. 83-124, hier S. 88.

21 Arno Buschmann, Gewalt und Frieden - zur Entwicklung der inneren Friedensordnung in Europa, in: Johann J. Hagen, Peter MAder (Hg.), Gewalt und Recht. Ringvorlesung zum 30-jährigen Bestehen der Rechtswissenschaftlichen Fakultät der Universität Salzburg, Frankfurt a.M. 1997, S. 11-33, hier S. 12. 
den römisch-deutschen im Kontext des deutsch-französischen Austauschs hilfreich scheint ${ }^{22}$. Insgesamt sei betont, dass gerade Buschmanns Definition, die auf Regelhaftigkeit und Rechtsbindung abhebt, insbesondere die staufische Landfriedensgesetzgebung reflektiert ${ }^{23}$. Für frühere Zeiten wären Modifikationen angebracht. Denn die Institution der Fehde veränderte sich während des Mittelalters sowohl in Bezug auf das Regelwerk als auch in Bezug auf die Stellung der Fehde im Rechtssystem ${ }^{24}$. Was das Regelwerk betrifft, ist an die Festlegung von Fehdegründen, an die Formalisierung von Fehdeankündigung und Fehdeabläufen, an die Verständigung auf legitime Schädigungsmethoden sowie an die Herausbildung der typischerweise fehdebeteiligten Gruppen zu denken. Mögliche Fehdegründe reichten von reiner Agonalität über die vom >deutschen Adel selten als Fehdegründe angeführten Argumente der Blutrache und der verletzten Ehre bis zum Hinweis auf verletztes Recht. Dabei kam eine spätmittelalterliche Fehdebegründung in der Regel nicht ohne Berufung auf einen Rechtsgrund aus. Die Bindung der Rechtmäßigkeit von Fehdeführung an die Einhaltung einer Absagefrist und die Zustellung einer Absage findet sich seit dem »Brandstifterbrief« Friedrich Barbarossas als normative Vorgabe, wobei später auch kürzere Absagefristen vorkamen. Gleichwohl ersetzten rechtlich fixierte, eindeutige Regeln hier die tendenziell mehrdeutige Form des fehdebegleitenden Rituals. Auch die zulässigen Maßnahmen wurden eingeschränkt; die Tötung des Gegners trat zurück, die Schädigung seiner materiellen Grundlagen wurde angestrebt. Die

$22 » \mathrm{~F}[\mathrm{ehde}]$ bedeutet das eigenmächtige und teilweise streng formalisierte Verfolgen von Rechtsansprüchen mit Gewalt. Ziel der F. war, ein Unrecht zu bestrafen oder den Gegner durch Schädigung und Erpressung zur Anerkennung des eigenen Rechtsstandpunktes zu zwingen«, vgl. Hans STADLER, Art. »Fehde«, in: Historisches Lexikon der Schweiz (HSL), Version vom 23.10.2006, URL: http://hls-dhs-dss.ch/textes/ d/D8606.php. Vgl. außerdem DERS., Art. »Guerre privée«, übersetzt aus dem Deutschen, Version vom 11.3.2008, URL: http://hls-dhs-dss.ch/textes/f/F8606.php: »Coutume caractéristique du Moyen Age européen, la guerre privée [all. Fehde, ancien franç. faide] était une sorte de procédure judiciaire, très formalisée dans certains de ses aspects, ayant pour but de venger une injustice ou d'obliger, par la force et les menaces, un adversaire à reconnaître ses torts«.

23 So mahnte Timothy ReUTER, Unruhestiftung, Fehde, Rebellion, Widerstand: Gewalt und Frieden in der Politik der Salierzeit, in: Stefan WeINFurter, Hubertus SEIBERT (Hg.), Die Salier und das Reich, Bd. 3, Sigmaringen ${ }^{2}$ 1992, S. 297-325, hier S. 306 zur Vorsicht »bei der Annahme einer allzu formalisierten, regelgebundenen Fehdeführung im 11. Jahrhundert« und S. 300 vor der Rückprojektion des »fast ritualisierte(n) Fehdewesen(s) des 14. und 15. Jahrhunderts ins 11. Jahrhundert«.

24 Die Veränderungen, die das Institut Fehde während des Mittelalters erfuhr, thematisierte bereits Otto Brunner. Freilich betonte Brunner auch die vermeintliche Kontinuität einer von der Germanenzeit bis ins 15./16. Jh. fortdauernden Dichotomie von Frieden und Fehde, vgl. BRUNNER, Land und Herrschaft (wie Anm. 20) S. 33f. 
Stellung im Rechtssystem schließlich wandelte sich zwischen der Karolingerzeit, in der das Königtum vermittels des von ihm beanspruchten Sühnezwangs versuchte, Fehdeführung zu unterbinden, über die Ottonenzeit, in der Fehde ein gängiges, jedoch durch Rituale >gezähmtes` Mittel inneradligen Konfliktaustrags war, bis zur staufischen Landfriedensgesetzgebung, die die Rechtmäßigkeit von Fehde an die Einhaltung bestimmter Formen, an das Vorliegen eines rechten Grundes und an das Subsidiaritäts- bzw. Komplementaritätsprinzip band. Zu guter Letzt bedarf die Bedeutung der Verwandtschaft für die Fehdeunterstützung einer neuerlichen Untersuchung. Während viele Arbeiten eine konstitutive Rolle der Verwandten als Helfergruppe postulieren, relativierte Regina Schäfer die Bedeutung der Verwandtschaft für die von ihr betrachteten gräflichen Fehden des Spätmittelalters ${ }^{25}$.

\section{Das Problem der Begrifflichkeit}

Wie das Phänomen der Fehde unterlag auch die Begrifflichkeit der Quellen einem Wandel. Nach den Erkenntnissen Julia Eulensteins vereindeutigte sich der Gebrauch der Begriffe aus dem Bedeutungsfeld der »Fehde« um 1400 im Deutschen. Zuvor operierte man mit einer Vielzahl oft miteinander kombinierter Begriffe wie criege, urleuge, misshelunge, vfleufe oder eben vede; auch das Lateinische kannte zahlreiche oft untechnische Begriffe (neben bellum und guerra noch rixa, inimicitia u.Ä.). Nach 1400 wurde in der Kurtrierer Kanzlei jedoch die Formulierung »Fehde« zu einem technischen Begriff ${ }^{26}$. Im Lateinischen blieben bellum und guerra dagegen weitgehend synonym.

${ }^{25}$ Regina SCHÄFER, Fehdeführer und ihre Helfer. Versuch zur sozialen Schichtung von Fehdenden, soll erscheinen in: Fehdeführung und Territorialisierungsprozess, hg. von Julia Eulenstein, Christine Reinle und Michael Rothmann (Drucklegung in Vorbereitung). Zu klären bliebe, ob die postulierte hohe Bedeutung der Sippe als Helferin in Fehdeangelegenheiten für das Frühmittelalter wirklich erwiesen werden kann.

26 Julia Eulenstein, Territorialisierung mit dem Schwert? Die Fehdeführung und Sühnepolitik des Trierer Erzbischofs Balduin von Luxemburg (1307/08-1354) im Erzstift Trier, Diss. phil. Gießen (2009), S. 18f.; Dies., Statt Krummstock das Schwert: Erzbischöfliche und adlige Fehdeführung im Erzstift Trier am Ende des 14. und im beginnenden 15. Jahrhundert, soll erscheinen in: Fehdeführung und Territorialisierungsprozess (wie Anm. 25). Zur lateinischen und deutschen Begrifflichkeit vgl. weiterhin SCHMOLINSKY/ARNOLD, Konfliktbewältigung im Mittelalter (wie Anm. 2), S. 37-39, zur lateinischen sowie niederdeutschen Begrifflichkeit vgl. außerdem Udo TEwES, Zum Fehdewesen zwischen Weser und Elbe, in: Lüneburger Blätter 21/22 (1970-1973), S. 121-200, hier S. 122f. Für die Stadt Frankfurt beobachtete Pierre Monnet ebenfalls eine zunehmende Vereindeutigung der Begrifflichkeit, in der für 
Dies leitet über zu einer letzten Vorüberlegung, nämlich zu dem im Rahmen des deutsch-französischen Ideenaustauschs aufkommenden Problem, den Begriff »Fehde« ins Französische zu übersetzen. Guerre privée, das gängige französische Analogon, scheint mir trotz Hans-Henning Kortüms

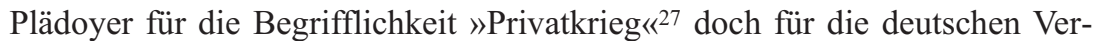
hältnisse unpassend zu sein, weil es von einer Konzentration der »öffentlichen Gewalt « beim Monarchen ausgeht ${ }^{28}$, die im Reich nicht nur gegenüber den Reichsfürsten nicht gegeben war, sondern auch bis zum 15. Jahrhundert von den Reichsfürsten nicht gegenüber dem Ritteradel geltend gemacht werden konnte. Die von der Kanonistik seit dem 11. Jahrhundert gerade mit Hinblick auf den Krieg neu entwickelte ${ }^{29}$ Unterscheidung einer öffentlichen

größere Auseinandersetzungen zunehmend der Begriff »krieg« gewählt wurde, vgl. Pierre MONNET, La ville et la guerre dans quelques cités de l'Empire aux XIV et $\mathrm{XV}^{\mathrm{e}}$ siècles: de l'urgence immédiate à la mémoire identitaire, in: Christiane RAYNAUD (Hg.), Villes en guerre, Aix-en-Provence 2008, S. 185-223, hier S. 187. Zur Formalisierung der »rechten Fehde« in der politischen Praxis des 15. Jahrhunderts vgl. Ernst SCHUBERT, Fehden, Söldner, Kriegsführung im späten Mittelalter, in: Bernd Ulrich Hucker, Ernst Schubert, Bernd WeisBrod (Hg.), Niedersächsische Geschichte, Göttingen 1997, S. 251-255, hier S. 251.

27 KorTÜM, Wissenschaft im Doppelpaß? (wie Anm. 3), S. 610. Hingegen hielten SCHMOLINSKY/ARNOLD das Kriterium »öffentlich" und "privat « für ungeeignet, um Krieg und Fehde zu unterscheiden, vgl. DIES., Konfliktbewältigung (wie Anm. 2), S. 38, Anm. 57. Im Übrigen wird der Begriff bellum privatum zur Beschreibung unterschiedlicher Konzepte verwendet, die sich mit dem der »Fehde« nicht decken. Während Thomas von Aquin einen tätlich ausgetragenen Streit (rixa) gleichsam für ein bellum privatum hielt, »quod inter privatas personas agitur non ex aliqua publica auctoritate, sed magis ex inordinata voluntate«, und diesen Streit (nicht aber zwingend die Selbstverteidigung in diesem!) für sündhaft erklärte, definierten die spätmittelalterlichen Juristen das bellum privatum anders. Für sie handelte es sich um eine Spielart des bellum particulare, das seinerseits als Umsetzung des Notwehrprinzips definiert war, vgl. Thomas von Aquin, Summa Theologica II-II, 34-56, übers. von Heinrich M. Christmann und Bernward DiETSChe, kommentiert von Josef EnDRES, Heidelberg u.a. 1966 (Die deutsche Thomasausgabe, 17B), II, 41.1, S. 98; zu den Ausführungen der Juristen zum bellum privatum vgl. Anm. 32.

28 Wilhelm JANSSEN, Art. »Krieg«, in: Geschichtliche Grundbegriffe 3 (1982), S. 567615, hier S. 574 machte, den oben vorgebrachten Gedanken präzisierend, das Innehaben der summa potestas iudicandi zum zentralen Kriterium für die Unterscheidung einer persona publica von einer persona privata. Im Gegensatz zu diesem Postulat war das spätmittelalterliche Reich durch sich überlagernde rechtliche Kompetenzen konkurrierender Instanzen charakterisiert.

29 In der frühmittelalterlichen Begrifflichkeit gibt es keine Homogenität. So weist Christoph Meyer darauf hin, dass in den Bußbüchern Fehde und Krieg nicht gleichgesetzt worden seien, ja, Krieg bisweilen sogar als bellum publicum aufscheine, während der Chronist Gregor von Tours Fehde und Krieg in eins setzte, vgl. MEYER, 
Gewalt von einer privata potestas, auf die Ernst-Dieter Hehl so nachdrücklich hingewiesen hat ${ }^{30}$, hatte im Reich bis zum Ende des Mittelalters keinen »Sitz im Leben $\aleph^{31}$. Und auch der Hinweis auf die gelehrt-juristische Unterscheidung zwischen einem bellum publicum und einem bellum particulare führt nicht weiter. Zwar darf man Fehden in der Tat die Bindung an das Interesse der Allgemeinheit absprechen und sie damit gleichsam zu »Einzelkonflikt[en] « erklären ${ }^{32}$. Doch die Gleichsetzung der im gelehrten Recht diskutierten »universalen« oder »öffentlichen« Kriege (bella publica), also solchen, die zwischen Parteien geführt würden, welche keinen Oberen mehr anerkannten und die außerdem dem Postulat nach zum Wohl der

Freunde (wie Anm. 12), S. 259f. Die Belege, die von einer Differenzierung zwischen Adelsfehde und königlicher Militäraktion ausgehen, müssen daher sorgfältig kontextualisiert werden. Ein Beispiel für die Privilegierung einer expeditio des Königs gegenüber anderen kriegerischen Handlungen bietet der Kölner Gottesfriede von 1083. Demnach wurden die Friedensbestimmungen in bestimmten Situationen außer Kraft gesetzt: »Excipitur etiam ab hac pace constitutione, si dominus rex publice expeditionem fieri iusserit propter appetendos regni inimicos vel concilium sibi habere placuerit propter diiudicandos iusticie adversarios«, vgl. Die Kopiar- und Urbarüberlieferung des Klosters Hardehausen des 12. bis 14. Jahrhunderts, eingeleitet und hg. von Horst CONRAD, Münster 2001 (Vereinigte Westfälische Adelsarchive, 14), S. 37-42, hier S. 41 (nach neu entdeckter weiterer Handschrift).

30 HeHL, Die Sorge für den Landfrieden (wie Anm. 6), S. 57.

${ }^{31}$ Erst am Ende des 15. Jh. finden meiner Kenntnis nach Reflexionen über die »privata persona non utens publica potestate «, die nicht berechtigt sei, Zwangsgewalt auszuüben, Eingang in die politisch-juristische Reflexion im Reich, vgl. etwa: Gabriel Biel, Collectorium circa quattuor libros Sententiarum. Libri quarti pars secunda (dist. 1522), hg. von Wilfridus Werbeck und Udo Hofmann, Tübingen 1977, Distinctio 15 qu. 3 not. 5, S. 39 .

32 Mit dieser Formulierung wird eine Bezeichnung aufgegriffen, die Markus Schrödl freilich in abweichender Nuancierung - ins Spiel gebracht hatte. Als »Einzelkonflikt« bezeichnet Schrödl nämlich das von den gelehrten Juristen Johannes de Lignano $(† 1383)$, Antoninus von Florenz $(\dagger 1459)$ und Sylvester de Prierio $(\dagger 1527)$ beschriebene bellum particulare, das vom bellum publicum unterschieden wurde, vgl. SCHRÖDL, Kriegsrecht (wie Anm. 10), S. 173. Zwei rechtmäßige Spielarten des bellum particulare wurden von den Juristen akzeptiert, das bellum iustum defensionis bzw. das bellum privatum und die Repressalie; als unrechtmäßig galt das Duell. Dabei folgte das bellum iustum defensionis den Regeln des Notwehrrechts (zu jenem vgl. S. 174-202), die enger gefasst waren als das Fehderecht. Vermittels der Repressalie verteidigte ein Gemeinwesen einen seiner Bürger, der keine Gerechtigkeit erlangen konnte (a.a.O., S. 203). Obwohl bellum privatum und Fehde demnach nicht deckungsgleich sind, ist zu bemerken, dass die Bezeichnung eines Konflikts als bellum privatum diesen nicht delegitimierte, sondern ihn vielmehr in ein definiertes Regelwerk einband. 
Christenheit bzw. aus Gründen des Gemeinwohls geführt wurden ${ }^{33}$, mit den Kriegen des römisch-deutschen Königs trifft nicht zu. Viel zu sehr waren die Herrscher nämlich in kleinteilige Konflikte mit Herrschaftskonkurrenten verstrickt, die sie allein zum Vorteil ihres Hauses und nicht des Reichs führten ${ }^{34}$. Daher scheint mir das altfranzösische Wort la faide eher geeignet, »Fehde« ins Französische zu übersetzen. Auch der Verfremdungseffekt, der durch den Rückgriff auf ein altfranzösisches Wort entsteht, kann als Vorteil empfunden werden.

\section{Die Zulässigkeit der Fehde nach Quellen der Rechtspraxis}

Welche Belege können nun für die postulierte Einbindung der Fehde in das rechtliche Normensystem und damit für die Legitimation von Fehden gebracht werden 35 ? Auf den ersten Blick scheint es, als thematisierten Rechtsquellen die Fehde nur im Medium des Verbots. Hinzu kommt, dass das Fehdewesen des römisch-deutschen Reichs kaum je theoretisch reflektiert wurde. Eine Ausnahme stellt hier vor allem der Theologe und Kanonist Heinrich von Gorkum (1378-1431) dar ${ }^{36}$, der die Fehdepraxis des Reichs

33 SCHRÖDL, Kriegsrecht (wie Anm. 10), S. 25-27; vgl. auch KEEN, Laws of War (wie Anm. 5), S. 68, 78.

34 Dies war auch die Meinung des Erasmus von Rotterdam, der den Fürsten seiner Zeit zuschrieb, zumeist um privater Angelegenheiten willen Krieg zu führen, vgl. Opvs Epistolarvm Des. Erasmi Roterodami denvo recognitvm et avctvm per P[ercy] S[tafford] Allen, 12 Bde., Oxford 1906-1958, Bd. 1, 1484-1514, Oxford 1906, Nr. 288, S. 551-554, hier S. 554, Brief des Erasmus an den Abt von St. Bertin, Antonius von Bergen, vom 14.3.1514; Hans-Rüdiger SCHWAB, Bekenntnisse eines Unpolitischen? Zum Friedensdiskurs des Erasmus von Rotterdam, in: Norbert BRIESKORN, Markus Riedenauer (Hg.), Suche nach Frieden: Politische Ethik in der Frühen Neuzeit, Bd. 2, Stuttgart 2002 (Theologie und Frieden, 20), S. 71-103, hier S. 93. Erasmus schrieb: »Quod si propius inspicias, pleraque priuata sunt principum ob quae bellum suscipitur. Quaeso te, an hoc humanum censes, mox orbem ad arma commoueri, quotiens hic aut ille princeps ob quiduis stomachatur in principem aut fortasse stomachum simulat?«

35 Zur ausführlicheren Darstellung der folgenden Überlegungen: Vgl. Christine REINLE, Innovation oder Transformation? Die Veränderung des Fehdewesens im Spätmittelalter, in: Christian Hesse, Klaus Oschema (Hg.), Aufbruch im Mittelalter - Innovationen in Gesellschaften der Vormoderne. Studien zu Ehren von Rainer C. Schwinges, Ostfildern 2010, S. 198-230, hier S. 201-206. Die Belege können hier daher etwas knapper gehalten werden.

${ }^{36} \mathrm{Zu}$ Heinrich von Gorkum vgl. Antonius Gerardus WeILER, Heinrich von Gorkum $(†$ 1431). Seine Stellung in der Philosophie und der Theologie des Spätmittelalters. 
explizit mit der Lehre vom gerechten Krieg kontrastierte und der sich entsprechend kritisch mit den bella bzw. guerrae im Reich auseinandersetzte. Dennoch kam auch er nicht umhin, zuzugeben, dass es sich bei der Fehdepraxis um eine »antiqua consuetudo [...] in imperio«, also eine Rechtsgewohnheit im Reich, handelte ${ }^{37}$.

\section{Rechtsbücher und Gerichtsquellen}

Auch wenn es also kaum legitimierende Diskurse im Sinne von Erörterungen gibt, thematisieren doch Quellen der Rechtspraxis die Position der Fehde im rechtlichen Gefüge. Dies gilt bereits für Rechtsbücher wie den »Sachsenspiegel«, der zwar nicht die Fehde als Ganzes, wohl aber die Modalitäten der Absage und die lehnrechtlichen Folgen der Absage eines Lehnsmanns gegenüber seinem Lehnsherrn und eines Lehnsherrn gegenüber seinem Lehnsmann behandelt. War eine Rechtsverletzung zu beklagen, verwies Eike von Repgow im Landrechtsteil des Sachsenspiegels den Geschädigten auf das ordentliche Gericht und bei Rechtsverweigerung an das königliche Gericht. Anders verhält es sich dagegen im Lehnrechtsteil: Hier wurde die Absage ins Spiel gebracht, die lediglich mündlich vorgebracht werden musste und auf die erst nach einer 24-Stunden-Frist die Schädigung folgen durfte ${ }^{38}$. Bestimmte Fehdepraktiken wurden allerdings im Land- wie im Lehnrechtsteil unter

Deutsch von Frans StOKS, Hilversum u.a. 1962; H[enri]. A[drien]. KroP, De leer van de rechtvaardige oorlog in de late middeleeuwen. Hendrik van Gorkums tractaat $\gg$ De justo bello«, in: Axel J. BRAND (Hg.), Oorlog in de middeleeuwen, Hilversum 1989, S. 111-124, bes. S. 116f. sowie die bei ReINLE, Innovation (wie Anm. 35), Anm. 2 zusammengestellte Literatur.

${ }^{37}$ Henricus de Gorrichem, De iusto bello, in: Tractatus consultatorii venerandi magistri Henrici de Gorychum, Köln 1503, fol. 50r-56r, hier fol. 55ar (künftig: Heinrich von Gorkum, De iusto bello). Benutzt wurde das Exemplar der Stadtbibliothek Trier, Inc. $14458^{\circ}$. Einen Wiederabdruck nach der Ausgabe Köln 1503 sowie eine Transkription bietet Vico AllegretTi, Sed bellum contrariatur paci. Guerra giusta e ingiusta: istituzioni, Ravenna 1997 (freundlicher Hinweis von Dr. Gisela Naegle, Gießen/Paris); auch diese Ausgabe wurde eingesehen. Eine Übersetzung des Traktats ins Niederländische fertigte $\mathrm{H}$ [enri] A[drien] KROP an, vgl. Hendrik van Gorkum, De rechtvaardige oorlog, in: Axel J. BRAND (Hg.), Oorlog in de middeleeuwen, Hilversum 1989, S. $151-172$.

38 Hans FEHR, Das Waffenrecht der Bauern im Mittelalter, in: Zeitschrift der SavignyStiftung für Rechtsgeschichte, Germ. Abt. 35 (1914), S. 111-211, hier S. 167-171; Sachsenspiegel. Lehnrecht, hg. von Karl August ECKHARDT, Göttingen, Berlin, Frankfurt a.M. ${ }^{2} 1956$ (Germanenrechte, Neue Folge), Art. 76, § 5-7. 
erhebliche Strafen gestellt ${ }^{39}$. Gleichwohl belegt der Sachsenspiegel, dem der Schwabenspiegel in leicht veränderter Form folgt ${ }^{40}$, die Zulässigkeit von Befehdung.

Daher dürfte es kein Zufall sein, dass drei der seltenen Belege für die Anerkennung von Fehdeführung vor Gericht ebenfalls aus Rechtsgutachten des sächsischen Raums stammen. Hier kann auf ein Urteil von Rechtskundigen des Magdeburger Schöffenstuhls verwiesen werden, das 1454 in der Auseinandersetzung eines äußerst fehdeaktiven Adligen, des späteren »Prinzenräubers« Kunz von Kauffungen, mit dem sächsischen Kurfürsten erging. Nach Meinung der Magdeburger Schöffen stand Kunz von Kauffungen prinzipiell ein Fehderecht $\mathrm{zu}^{41}$. In einem weiteren Fall erklärten die Magdeburger Schöffen nach Ansicht von Mattias Fischer die Existenz eines Fehdebriefs zum alleinigen Indikator für die Rechtmäßigkeit einer Fehde ${ }^{42}$. Beim dritten Beispiel ging ein Gericht, dem 1454 die Klage des Kölner Erzbischofs und Paderborner Bistumsverwesers Dietrich von Moers gegen Vertreter zweier westfälischer Adelsfamilien wegen deren Fehdetätigkeit unterbreitet wurde, davon aus, dass das, was in rechter Fehde geschehen sei,

39 Sachsenspiegel, Landrecht, hg. von Karl August ECKHARDT (Germanenrechte, Neue Folge), Göttingen, Berlin, Frankfurt a.M. ${ }^{2} 1955$, II, 13, 45; Antje HolZHAUER, Rache und Fehde in der mittelhochdeutschen Literatur des 12. und 13. Jahrhunderts, Göppingen 1997 (Göppinger Arbeiten zur Germanistik, 639), S. 191.

40 Der Schwabenspiegel. Normalform, hg. von Karl August ECKHARDT, Aalen 1972 (Studia iuris Suevici, 5; Bibliotheca rerum historicarum. Studia, 8), hier Lehnrecht 153a, b, S. 393f.

${ }^{41}$ Hierzu vgl. die Belege bei ReInLE, Innovation (wie Anm. 35), S. 202, Anm. 16; ferner: Michael RockMANN, Die Schöffensprüche aus Magdeburg und Leipzig von 1455 im Schiedsverfahren zwischen Kunz v. Kauffungen und Kurfürst Friedrich II. von Sachsen, in: EMIG, Der Altenburger Prinzenraub (wie Anm. 20), S. 257-294, hier S. 282; Heiner LÜCK, Kunz von Kauffungen versus Kurfürst Friedrich II.: Das misslungene Schiedsverfahren als Auslöser des Prinzenraubs, in: EMIG, Der Altenburger Prinzenraub, S. 235-256 (zu den Schöffensprüchen in der Kauffungen-Affäre). Zum Magdeburger Schöffenspruch vgl. bes. S. 250. Lück verdanken wir den instruktiven Hinweis, dass der Magdeburger Schöffenstuhl »bis in das 16. Jahrhundert einer auf Laien beruhenden Spruchtätigkeit verhaftet« blieb. In der Kauffungen-Affäre ebenfalls befragt wurde der Leipziger Schöffenstuhl, der jedoch zu einem für Kauffungen ungünstigen Urteil kam. Nach Lück hatte sich dieser Schöffenstuhl seit der Gründung der Universität Leipzig 1409 dem gelehrten Recht geöffnet. Doch selbst die Schiedsrichter, die im Juni 1455 über die Forderungen des Kunz gegen Herzog Friedrich II. von Sachsen urteilten, vermochten sich eine Konstellation vorzustellen, in der »Cuncz fehedehalben, mit des romischen koniges, ader mit fursten der lande willen, die er bewiesen konde, und sich darinnen gehalden, hette, also recht ist, solliche tat, begangen und gethan hette von rechtis wegen « (RocKMANN, Nr. 5, S. 290).

42 Vgl. FISCHER, Reichsreform (wie Anm. 2), S. $30 \mathrm{f}$. 
nicht zu strafen $\operatorname{sei}^{43}$. Doch auch in Bayern konnten sich zwei hochrangige Adlige vor dem Hofgericht der bayerischen Herzöge darüber streiten, ob die Überreichung eines »Feindsbriefs« den gängigen Fehderegeln entsprach oder nicht. Ja, selbst vor dem königlichen Gericht konnte man sich auf das Fehderecht berufen! ${ }^{44}$ Als letztes Beispiel sei auf ein Weistum hingewiesen, in dem Rechtsgewohnheiten außerhalb des sächsischen Rechtsraums thematisiert werden. Es stammt aus dem an die Kurpfalz verpfändeten, am Rhein gelegenen Oppenheim. Hier regelten Schultheiß, Bürgermeister und Rat zu Oppenheim 1419, unter welchen eng definierten Bedingungen die Oppenheimer Bürger Fehde (kriege) zur Einforderung ihrer Rechtsansprüche einsetzen durften ${ }^{45}$. Zuzugeben ist, dass solche Quellen selten sind. Doch scheinen mir gerade Quellen aus dem Umfeld von Rechtsprechung und Rechtsweisung die Zulässigkeit von Fehde besonders gut zu belegen, da hier vorgebrachte Argumente in besonderem Maß überprüfbar sein mussten und außerdem nicht offen dem Recht widersprechen konnten.

\section{Der »Selbsthilfevorbehalt« in Lehens- und Pfandurkunden sowie bei Sühnelehen}

Sehr viel häufiger wird der Fehde jedoch in Urkunden gedacht. Sowohl bei Bestallungen von Funktionsträgern und Verpfändungen wie bei Belehnungen sind Bestimmungen zu finden, die ich als »Selbsthilfevorbehalt« bezeichnen möchte. Sie regeln den Umgang dessen, der ein bestimmtes Objekt erhalten hat, mit diesem Objekt für den Fall, dass dem Begünstigten Unrecht geschieht. Zuerst muss er wegen dieses Unrechts Klage vor dem Eigentümer des Objekts (in der Regel dem Landes- oder Lehnsherrn) erheben. Bleibt seine Rechtssuche aber ergebnislos, wird ihm nach Ablauf einer zuvor festgelegten Frist zugestanden, sich selbst des Unrechts zu erwehren. Oft wird ihm außerdem eingeräumt, sich dazu des ihm überlassenen Objekts zu

43 Leopold GRÜE, Die Spiegel-Westphalensche Fehde. Eine Episode aus der Geschichte des westfälischen Adels im 15. Jahrhundert, in: Westfälische Zeitschrift 47/II (1887), S. 3-32, hier S. 31; zu diesem und einem weiteren Beleg aus dem hessischen Raum vgl. ReINLE, Innovation (wie Anm. 35), S. 202f., Anm. 17-18.

44 Wilhelm BECK, Ein Zweikampf zu Pferd 1464, in: Archivalische Zeitschrift N. F. 19 (1912) S. 285-312, hier S. 290f.; Deutsche Reichstagsakten (Ältere Reihe), hg. durch die Historische Kommission bei der Bayerischen Akademie der Wissenschaften, Bd. 5: Deutsche Reichstagsakten unter König Ruprecht, 1. Abt. 1401-1405, hg. von Julius WeIzsÄCKER, Gotha 1885, ND Stuttgart 1956, Nr. 334-336, S. 453-467.

45 StA Darmstadt Bestand B 15 Nr. 158 (1419 Juli 28); Regest: www.hadis.hessen. de/scripts/HADIS.DLL/home?SID=5EBE-1FC9007-BDF15\&PID=EE64 (Zugriff vom 15.08.2011). 
bedienen, »um sich selbst zu helfen" (d.h. um Fehde zu führen) ${ }^{46}$. Solche »Selbsthilfevorbehalte« finden sich in der zweiten Hälfte des 14. sowie der ersten Hälfte des 15. Jahrhunderts in manchen landgräflich-hessischen Lehnsurkunden ${ }^{47}$. Auch aus dem welfischen Bereich können Belege beigebracht werden, wobei hier die Pfandurkunden zu dominieren scheinen ${ }^{48}$.

Auch in einer dritten Urkundengattung findet man solche Selbsthilfevorbehalte, nämlich bei der Vergabe von Sühnelehen. Hier wurde bisweilen der unterlegenen Seite eingeräumt, wieder zur Selbsthilfe zu greifen, wenn sie sich vergeblich vor dem Fürsten und damit dem Landesherrn »in spe« um Recht bemüht hatte ${ }^{49}$. Darüber hinaus gestatten auch Urfehden bisweilen einem unterlegenen, Racheverzicht schwörenden Gegner, im Dienste seines eigenen Herrn doch wieder an einer Fehde teilzunehmen ${ }^{50}$. Noch 1485 und

46 Zur Begrifflichkeit der Quellen vgl. etwa die Belehnungsurkunde Heinrichs d.Ä., Heinrichs und Boddes v. Budenhausen vom 15. Dezember 1458 mit Schloss Arnstein als rechtem Mannlehen (und herzoglichem Offenhaus). Die Belehnten versprachen u.a. »Dan were das wir eyniche sache mit imande zcu thünde hetten, von dem selben sollen ir gnade vns rechtes helffen bynnen zwen maynden, dar nach als wir irer gnade darümb manen abe sie mogen. Muchten sie des aber nicht gethün, so mogen wir vns von dem selben huße behelffen, des besten wir mogen « (StA Marburg, Urkunden 14, Nr. 2503; vgl. außerdem StA Marburg, Lehenbuch 3, fol. 53r-55v mit Eintrag vom 16.12.1458). Als Beispiel aus dem welfischen Gebotsbereich sei die Verpfändung eines Burglehens auf Schloss Calenberg durch Johann v. Salder und seine Söhne an Conrad v. Linde am 21.02.1361 genannt, bei der u.a. Folgendes vereinbart wurde: »wert ichte men on vor vnrechtede vn he eder sine eruen vs dat weten lete so sculde we ome helpen minne eder rechtes binnen ver weken wo we des niht enteden so mochte he sik irweren vte deme Borchlen to deme kalenberghe So lange byt ome recht begeghente Ane gyghen vsen heren van Luneborch vnde de Sine«, vgl. Urkundenbuch zur Geschichte der Herzöge von Braunschweig und Lüneburg und ihrer Lande, gesammelt und hg. von H[ans] SudENDORF, 10 Teile, Hannover 1859-1880, sowie 11. (Register-)Theil, bearbeitet von C[arl] SATTLER, Göttingen 1883, hier Bd. 3, Nr. 131, S. 83.

47 Siehe Anhang I.

48 Siehe Anhang II.

49 Siehe Anhang III.

50 So in den Urfehdeurkunden der Stadt Göttingen, vgl. Andrea BoocKmanN, Urfehde und ewige Gefangenschaft im mittelalterlichen Göttingen, Göttingen 1980 (Studien zur Geschichte der Stadt Göttingen, 13), S. 22; zu diesem und den im Folgenden angeführten Beispielen vgl. auch ReINLE, Innovation (wie Anm. 35), S. 203f. Ergänzt werden kann die Sühne Eckhards v. Felsberg mit Landgraf Hermann II. von Hessen. Eckhard versprach am 29.5.1388, nichts gegen den Landgrafen zu unternehmen und sich bei Streitigkeiten mit landgräflichen Mannen und Untertanen zunächst an den Landgrafen $\mathrm{zu}$ wenden. Auch ihm wurde eingeräumt, sich bei Rechtsverweigerung »von deme ader den selbs rechts helffin vnd die irmanen ob ich kunde«. Gegen den 
1510 musste Herzog Johann II. von Kleve-Mark den Ritterschaften von Kleve und Mark als Entgegenkommen für Steuerbewilligungen bestätigen, dass sie, wenn sie mit einem Auswärtigen um eine Sache stritten, diesen um die strittige Sache »mahnen und fordern« dürften, falls der Herzog ihnen nicht innerhalb einer gesetzten Frist auf gütlichem Weg zu ihrem Recht verholfen hatte ${ }^{51}$. Bezeichnend dürfte jedoch sein, dass diese Erlaubnis zur Selbsthilfe am Ende des 15. Jahrhunderts auf Auseinandersetzungen mit Auswärtigen beschränkt wurde.

Die Begrifflichkeit der Quellen regt dazu an, die Forschungsdebatte um den Begriff »Selbsthilfe « nochmals in erweiterter Form aufzunehmen ${ }^{52}$. Denn die Einordnung der Fehde als Selbsthilfe wurde in jüngerer Zeit seitens der Rechtshistoriker zunehmend in Frage gestellt. Hingegen hat Mattias Fischer den Selbsthilfebegriff in Bezug auf die Fehde als »wertneutralen Gegenbegriff zur Gerichtshilfe« sowie unter Berufung auf Schünemann als »)Synonym für den eigenmächtigen Rechtsschutz in allen seinen Erscheinungsformen «« weiterhin für brauchbar erklärt ${ }^{53}$. Jüngst hat hingegen Martin Pilch die rechtshistorischen Bedenken bekräftigt. Seiner Auffassung nach gewinnt der Begriff ")Selbsthilfe $[\ldots]$ nur aus dem Gegenbegriff der staatlichen Rechtsdurchsetzung Sinn [...], im Rahmen welcher sie als subsidiär geduldetes Vorgehen bei Gefahr im Verzug - hierin mit verwandten Zügen zur Notwehr - ihren Platz findet. In dezidiert vorstaatlichen Verhältnissen fehlt aber dieses begriffliche Gegenstück, weshalb auf die Kennzeichnung von Fehde und Blutrache als $\gg$ Selbsthilfe $<$ besser verzichtet werden sollte ${ }^{54}$. Nun wird man in der Tat im spätmittelalterlichen römisch-deutschen Reich nicht von durchgängiger staatlicher Rechtsdurchsetzung ausgehen wollen. Aber der Blick in die angeführten Quellen lehrt, dass Fehde noch im Spätmittelalter als Mittel betrachtet wurde, den eigenen Ansprüchen zum Durchbruch zu verhelfen

Landgrafen selbst stand Eckhard aber nur ein Klagerecht zu, vgl. StA Marburg, Urkunden 8, Nr. 183.

${ }^{51}$ Hermann Rothert, Das mittelalterliche Fehdewesen in Westfalen, in: Westfälische Forschungen 3 (1940), S. 145-155, hier S. 152. Rothert interpretiert das erwähnte »Mahnen und Fordern« ibid. als Erlaubnis zur Fehdeführung.

52 Zum Begriff »Selbsthilfe« vgl. zusammenfassend Christine REINLE, »Fehde« und gewaltsame Selbsthilfe in England und im römisch-deutschen Reich, in: Rolf LIEBERWIRTH, Heiner LÜCK (Hg.), Akten des 36. Deutschen Rechtshistorikertages, Halle an der Saale, 10.-14. September 2006, Baden-Baden, Bern, Stuttgart 2008, S. 99-132, hier S. 106, Anm. 24.

53 Vgl. FiscHER, Reichsreform (wie Anm. 2), S. 15.

54 Vgl. Martin PILCH, Der Rahmen der Rechtsgewohnheiten. Kritik des Normensystemdenkens entwickelt am Rechtsbegriff der mittelalterlichen Rechtsgeschichte, Wien, Köln, Weimar 2009, S. 153f. (freundlicher Hinweis von Prof. Dr. Martin Kintzinger, Münster). 
und damit sich selbst zu helfen, wenn der von den werdenden Landesherren bevorzugte rechtliche Austrag nicht Platz griff. Insofern kann meines Erachtens am Selbsthilfebegriff festgehalten werden.

\section{Burgfrieden, Turnierordnungen und Landfriedensverträge}

Kann man aus den vorgenannten Beispielen ersehen, dass Übergeordnete die Fehden niedriger stehender Personen unter genannten Bedingungen akzeptierten, so gilt diese Akzeptanz der Fehde erst recht in jenen Beziehungen, in denen Adlige sich auf gleicher Ebene begegneten. $\mathrm{Zu}$ denken ist hier an die Fehdeklauseln in Burgfrieden ${ }^{55}$, an die Bezugnahme auf Fehderegeln in Turnierordnungen ${ }^{56}$ oder das Versprechen der Fehdehilfe in Rittergesellschaften ${ }^{57}$. Ferner sei noch auf die Fehdeklauseln in Verträgen ${ }^{58}$, speziell in Landfriedensverträgen, hingewiesen, die ebenfalls Regelungen für Streitfälle jener Leute enthielten, für die die Fürsten bindende Verpflichtungen eingehen

55 Vgl. z.B. den Waldecker Burgfrieden des Jahres 1422, hierzu Wolfgang KLÖTZER, Der Waldecker Burgfrieden. Ein Beitrag zur Geschichte der mittelrheinischen Ganerbschaften, in: Nassauische Annalen 78 (1967), S. 62-74, hier 70f., Nr. 4-6, 10, 15.

56 Vgl. die Heilbronner Turnierordnung des Jahres 1485, zu ihr Heide STAMm, Das Turnierbuch des Ludwig von Eyb (cgm 961). Edition und Untersuchung. Mit einem Anhang: Die Turnierchronik des Jörg Rugen (Textabdruck), Stuttgart 1986 (Stuttgarter Arbeiten zur Germanistik, 166), S. 207, 209.

57 Rainer DeCKER, »Ubi lis continua et pax est rara«. Die Fehden im Süden des Bistums Paderborn gegen Ende des 14. Jahrhunderts, in: Johannes ALTENBEREND in Verbindung mit Reinhard Vogelsang (Hg.), Kloster - Stadt - Region. Festschrift für Heinrich RÜTHING, Bielefeld 2002 (10. Sonderveröffentlichung des Historischen Vereins für die Grafschaft Ravensberg), S. 235-250, hier S. $239 f$.

58 So enthielt die »sune vnd vruntschaft«, die König Karl IV. zur Beendigung der »missehellunge, czweyung, vnd Kriege« zwischen den böhmischen Edlen Wilhelm v. Landstein und Heinrich v. Neuhaus am 12.7.1354 vereinbarte, u.a. folgende Bestimmung: »Vnd wanne der vorgenante Heinrich, dez egenanten Wilhelms, oder derselbe Wilhelm, dez obgenanten Heinrichs veynt werden wil, so sol ir ieclicher, den andern, ee er in an leibe oder an gute angreiffe, vier wochen, von erste, offentlich entsagen, vnd die entsagunge von erste, in dez Huse, do der, dem man entsagit, wonhaftig ist, vnd dornoch vf dem Rathuse zu Prage, mit gutem vrkunde vnd geczeugnůzze, der Ratleute doselbist, offentlichen kůnden«, vgl. Codex Diplomaticus et epistolaris Moraviae. Urkunden-Sammlung zur Geschichte Mährens, im Auftrag des mährischen Landes-Ausschusses, hg. von Vincenz BrandL, Bd. 8: Vom Jahre 1350-1355, Brünn 1874, Nr. 269, S. 204f.; vgl. ferner Urkundenregesten zur Tätigkeit des deutschen Königs- und Hofgerichts bis 1451, hg. von Bernhard DiestelkamP, Bd. 6: Die Königszeit Karls IV. (1346-1355 März), bearbeitet von Friedrich BATTENBERG, Köln, Wien 1990 (Quellen und Forschungen zur höchsten Gerichtsbarkeit im Alten Reich), Nr. 576, S. 346f. 
konnten. Sie belegen ebenso wie die Fehdevorbehalte in Belehnungs- oder Verpfändungsurkunden, dass nicht nur die an dem Fortbestand der Fehde interessierten Niederadligen, sondern auch deren Herren, die künftigen Landesherren, bis ins 15. Jahrhundert hinein Fehde unter bestimmten Konditionen zulassen mussten.

So vereinbarten am 20. März 1405 Erzbischof Johann von Mainz, die Herzöge Bernhard und Heinrich von Braunschweig-Lüneburg, Herzog Otto von Braunschweig sowie Landgraf Hermann von Hessen, niemand solle sich während ihres auf sechs Jahre geschlossenen Landfriedens an einem anderen »vergreifen oder ihm Schaden thun «, wenn er nicht vorher Feind desselben geworden sei und sich seiner Ehre gegen ihn verwahrt habe. Beabsichtigte jemand aus Feindschaft eine Abklage, so war eine Frist von sechs Wochen und drei Tagen vor dem Angriff auf das Gut des Gegners einzuhalten. Wer nicht zum Wappen geboren sei, solle keine eigenen Pferde unterhalten, »um damit auf Raub auszureiten« und »keine eigenen Ritte oder Fehden unternehmen « ${ }^{59}$. Umgekehrt ist aus solchen Bestimmungen zu schließen, dass bei

${ }^{59}$ SudENDORF, Urkundenbuch (wie Anm. 46), Bd. 10, Nr. 2, S. 6-12, hier S. 6 (zu den aus Sudendorfs Kopfregest entnommenen Zitaten). Im Vertrag selbst liest man: »Auch sal nymant ztu dem andern griffen adir en beschedigen, er werde danne sin fygent, vnde beware sich des von eynir sonnen ztu der andern kuntlich vnde uffinbar also daz ein tag vnde eyn nacht vor deme zugriffe vorgangen sy ane geuerde, Weriz auch daz ymant fÿgintschaff hette daz er abeclage thun wolde adir yme not were zu thunde dy mag er thun zu dren tagen vnde Ses wochen alse von alder gewontlich gewest ist, vnde sal doch der da bynnen an des gut adir dy sin an dem sollich abeclage geschen ist nicht griffen adir en dar an beschedigen dy czijt sy danne vor vorgangen alse vor geschreben stet. Auch wer nicht zu dem wapen geborn ist der sal keyne eygen pherde haben nach rouberige zu riden nach keyne eygene rydde adir fehde haben, vz gescheiden dy stede dy in dissen lantfredde kommen «, vgl. SudENDORF, S. 9. Vgl. einen weiteren Abdruck der Quelle in: RTA, Bd. 5 (wie Anm. 44), Nr. 476, S. 694-701, hier [9] S. 696, sowie die Wiedergabe des Regests in: Landgrafen-Regesten Online. Ein digitales Editionsprojekt der Historischen Kommission für Hessen in Zusammenarbeit mit dem Hessischen Landesamt für geschichtliche Landeskunde, bearbeitet von Otto VOLK, URL http://online-media.uni-marburg.de/ma_geschichte/lgr/, 2002ff., hier Nr. 11275 (Bearbeitungsstand des Regests vom 6.8.2008). Was die im Landfrieden von 1405 genannte persönliche Qualität des Fehdeberechtigten betrifft, fasse ich die Aberkennung der Fehdeberechtigung für die, die »nicht zu dem wapen geborn« sind, als Hinweis auf eine geforderte Wappenführung auf. Sudendorf gibt die Stelle in seinem Urkundenregest jedoch mit »zu den Waffen geboren« wieder, was auf Waffenfähigkeit verweist, ebenso interpretiert Tewes die Stelle, vgl. TewES, Zum Fehdewesen zwischen Weser und Elbe (wie Anm. 26), S. 140. So oder so verbirgt sich hinter der Formulierung ein Adelsvorbehalt. Wem die Wappenfähigkeit in Verbindung mit einer fehdeförmlichen Tat bestritten wurde, musste gemäß einem Landfrieden derselben Region aus dem Jahre 1395 beweisen, dass Großvater oder Vater ihm diese Wappenfähigkeit nach »rittirs edir rittirmesziger art« vererbt hatten, vgl. ibid., 
Einhaltung aller genannten Rahmenbedingungen, insbesondere einer fristgerechten Absage ${ }^{60}$, adlige Fehdeführung zulässig war. Auch Fehden Adliger gegen andere Fürsten wurden von werdenden Landesherren geduldet ${ }^{61}$.

\section{Fehde und Notwehr}

$\mathrm{Zu}$ guter Letzt sei noch auf eine Argumentationsfigur verwiesen, die bemerkenswert ist, weil sie die Umsetzung gelehrten Rechtsdenkens in die Rechtspraxis des römisch-deutschen Reichs belegt: So thematisierten in der Fehde des bayerischen Herzogssohns Ludwigs des Buckligen gegen seinen Vater Ludwig den Gebarteten die Helfer des aufständischen Sohns, dieser sei wegen seiner Zurücksetzung durch den Vater (zugunsten, wie sich ergänzen lässt, eines unehelich geborenen Bruders) zu seinem Aufstand gezwungen worden, »notwerehalb des aufczehallten und darwider zetun als dann das natürlich die were niemant verpoten ist «. Die Fehdeberechtigung wird hier

mit Verweis auf: Urkundenbuch der Reichsstadt Nordhausen, Teil 2, 1267-1703. Urkunden von Fürsten, Grafen, Herren und Städten, Adelsurkunden, von Gerhard MeISSNER, Nordhausen 1939, Nr. 68, S. 80-91, hier S. 90 f.

60 So ließ der Landfrieden König Wenzels für die Herzöge Wenzlaus und Albrecht von Sachsen und Lüneburg vom 25.7.1382 Fehde am vierten Tag nach ihrer Ankündigung zu: »wer aber sache, das dhein herre oder ymant anders frewntschaft, oder geselleschaft mit eim andern gehabt hette, vnd des sein ere bewaren wolte, vnd sein feynt sein wolte, daz sal er ym kunt tun vnd bewaren, biz vff den dritten tag, beuor ee er in angreife oder schaden twe an alle argelist«, vgl. SUDENDORF, Urkundenbuch (wie Anm. 46), Bd. 6, Nr. 13, S. 12f., hier S. 13.

${ }^{61}$ Als Beispiel für eine in Landfrieden festgehaltene Erlaubnis, Fehde zu führen, sei ein zwischen den Herzögen von Sachsen-Lauenburg, den Grafen von Holstein und den Städten Lübeck und Hamburg für zwei Jahre geschlossener Landfrieden aus dem Jahre 1374 angeführt. In diesem billigten sich Herren und Städte zu, »openbare orloghe« zu haben, während sie dieses Recht der Stadt- und Landbevölkerung absprachen, vgl. etwa FISCHER, Reichsreform (wie Anm. 2), S. 56. Die Duldung adliger Fehdeführung konnte sogar vertraglich zwischen Hoch- und Niederadligen vereinbart werden: Am 18.11.1386 erteilte Herzog Heinrich von Braunschweig-Lüneburg dem Ritter Rudolf v. Zellenstede und anderen Adligen die Erlaubnis, im Fall einer Fehde der Adligen mit Herzog Wenzlaus von Sachsen-Lüneburg, dessen Sohn Otto oder Herzog Bernhard von Braunschweig-Lüneburg sein Land und Gebiet zu durchqueren, bis sie ihr Recht erhielten, vgl. SuDENDORF, Urkundenbuch (wie Anm. 46), Bd. 6, Nr. 154, S. 167f. Diese Bestimmung muss als Erklärung der Bereitschaft, eine eventuelle Fehde nicht zu unterbinden, interpretiert werden. Umgekehrt pflegten sich zu interterritorialer Fehdebekämpfung bereite Partner dazu zu verpflichten, Befehder ihrer Vertragspartner nicht auf ihrem Territorium gewähren zu lassen. 
also aus dem Gedanken der Notwehr hergeleitet ${ }^{62}$. Dies entsprach einem Argumentationsmuster des gelehrten Rechts. Denn nach Johannes de Lignano, Antoninus von Florenz und Sylvester de Prierio war die Verteidigung der eigenen Person durch das Naturrecht erlaubt, nach Johannes de Lignano wurde sie außerdem vom positiven Recht gebilligt ${ }^{63}$. Dieselben Autoren sahen auch die Verteidigung des Eigentums durch das Notwehrrecht gedeckt. Selbst zur Verteidigung dritter, einem verbundener Personen konnte Notwehr (oder hier zutreffender: Nothilfe) ausgeübt werden ${ }^{64}$. Freilich war Notwehr zunächst als unmittelbare Abwehr eines gegenwärtigen Angriffs definiert. War der Angriff beendet, konnte sich der Geschädigte nicht mehr auf Notwehr berufen, wenn nicht ein neuer Angriff zu befürchten stand. Zur Rückgewinnung entfremdeter Güter galt hingegen eine Dreitagesfrist als zulässig. Einschränkungen wurden ferner für Art und Umfang der Verteidigung und die Motivation, die nicht von Rache geleitet sein durfte, formuliert ${ }^{65}$. Doch konnte der Gedanke des vim vi repellere licet auch weiter ausgedehnt werden und die zeitversetzte Rückholung von Gütern dann zulassen, wenn kein Recht von einer höheren Gewalt zu erlangen war'66. Damit wurde eine - wenn auch präzise definierte - Brücke zwischen dem Notwehrrecht, das etwa im Mainzer Reichslandfrieden von 1235 in Gegensatz zum Fehderecht gestellt war, und dem Fehderecht geschlagen ${ }^{67}$, die offenbar auch von anderen Fehdeführern betreten wurde ${ }^{68}$.

${ }^{62}$ Auf die instruktive Quelle wies Wild hin, vgl. Joachim WILD, Der Fehdebrief. Zur Diplomatik des Fehdewesens im Herzogtum Bayern, in: Hans-Joachim HECKER, Reinhard HeydenReuter, Hans Schlosser (Hg.), Rechtssetzung und Rechtswirklichkeit in der bayerischen Geschichte, München 2006, S. 99-122, hier S. 115. Die von Wild angegebene Signatur lautet: BayHStA München, Pfalz-Neuburg Urk., Bünde und Fehden 156.

${ }^{63}$ SCHRÖDL, Kriegsrecht (wie Anm. 10), S. 174.

64 Ibid., S. 177, 179-182.

65 Ibid., S. 187f., 191f. Weitere Bedingungen für die Anwendung des Notwehrrechts finden sich a.a.O., S. 192-202.

${ }^{66}$ Zum Grundsatz des vim vi repellere licet des römischen Rechts vgl. HeHL, Krieg, Individualisierung und Staatlichkeit (wie Anm. 6), S. 123; Dietrich KuRZE, Krieg und Frieden im mittelalterlichen Denken, in: Heinz DuchHARDT (Hg.), Zwischenstaatliche Friedenswahrung in Mittelalter und Früher Neuzeit, Köln, Wien 1991 (Münstersche Historische Forschungen, 1), S. 1-44, hier S. 8f.; ND in: DerS., Klerus, Ketzer, Kriege und Prophetien. Gesammelte Aufsätze, hg. von Jürgen SARnOwSKY, Marie-Luise Heckmann, Stuart Jenks, Warendorf 1996, Nr. 10, S. 344-392, hier S. 352; IsenMANN, Recht, Verfassung und Politik (wie Anm. 7), S. 129 sowie S. 132-134; DeRS., Reichsrecht und Reichsverfassung (wie Anm. 7), S. 609.

${ }^{67}$ Constitutiones et acta publica imperatorum et regum, Bd. 2, hg. von Ludwig WEILAND (MGH. Legum Sectio 4/2), Hannover 1896, Nr. 196, S. 241-247, hier S. 254, Art. 5: »Ad hoc magistratus et iura sunt prodita, ne quis sui doloris vindex sit, quia ubi 
Mit diesen Bemerkungen sei dieser Punkt abgeschlossen. Es wurde gezeigt, dass normative und präskriptive Texte sowie Dokumente mit Vertragscharakter die Fehde in einer Weise thematisierten, die von der Legitimität der Fehde ausgeht. In Anbetracht der ohnehin untechnischen Begrifflichkeit der Quellen verwundert es nicht, wenn die Rede von »Feindschaft« oder »Selbsthilfe« weit häufiger zu konstatieren ist als die Verwendung des Begriffs »Fehde«. Doch fügen sich diese Begriffe zu einem Handlungs- und Bedeutungsfeld »Fehde « zusammen. Geht man nun von einem weiteren Diskursbegriff aus, der unter »Diskurs« »nicht nur ein geregeltes Ensemble von Redeweisen, Redefunktionen und Sprachmustern, sondern auch ein festes Bündel tradierter Denk- und Konnotationsschemata « versteht ${ }^{69}$, kann man auch den Quellen der täglichen Rechtspraxis bescheinigen, einen Beitrag zum Diskurs über die Fehde geleistet zu haben.

Dies leitet zum zweiten Hauptpunkt meiner Ausführungen über: Sie beschäftigen sich mit der Analyse ausgewählter Faktoren, welche zur Delegitimation von Fehden führten.

iuris cessat auctoritas, excedit licencia seviendi. Statuimus igitur, ut nullus, in quacumque re dampnum ei vel gravamen fuerit illatum, se ipsum vindicet, nisi prius querelam suam coram suo iudice propositam secundum ius usque ad diffinitivam sentenciam prosequatur; nisi in continenti ad tutelam corporis sui vel bonorum suorum vim vi repellat, quod dicitur nothwere. Si quis aliter processerit ad vindictam, dampnum illatum adversario solvat in duplum, nulla actione sibi de dampnis vel gravaminibus illatis sibi de cetero competente«.

${ }^{68}$ Nach Grüe sollen sich auch die wegen ihrer Fehdeführung vom Domkapitel Paderborn angeklagten Niederadligen v. Westphalen 1454 u.a. darauf berufen haben, sie hätten gegen ihre Kontrahenten, die Spiegel, aus Notwehr gehandelt, vgl. GRÜE, Spiegel-Westphalensche Fehde (wie Anm. 43), S. 25. Auch Horneck v. Hornberg d.Ä. und seine Söhne sowie vice versa Pfalzgraf Otto, ihr Gegner, sollen sich 1438 zur Rechtfertigung ihrer Fehde auf das Notwehrrecht bezogen haben, vgl. Hermann EHMER, Horneck von Hornberg. Raubritter oder Opfer fürstlicher Politik, in: Kurt ANDERMANN (Hg.), »Raubritter« oder »Rechtschaffene vom Adel«? Aspekte von Politik, Friede und Recht im späten Mittelalter, Sigmaringen 1997 (Oberrheinische Studien, 14), S. 65-88, hier S. 81f. Gleiches gilt für die Reichsstadt Ulm und andere schwäbische Städte, die sich 1457 wegen des Bruchs eines Rechberg'schen Schlosses, das sie für ein Raubschloss hielten, vor dem Grafen von Württemberg als gewillkürtem Richter rechtfertigen mussten. Sie beriefen sich auf den Grundsatz des vim vi repellere licet und machten ihr Recht auf Notwehr geltend, vgl. IsENMANN, Reichsrecht und Reichsverfassung (wie Anm. 7), S.609. Vgl. ferner Janine FeHN-Claus, Erste Ansätze einer Typologie der Fehdegründe, in: Horst BRUNNER (Hg.), Der Krieg im Mittelalter und in der Frühen Neuzeit: Gründe, Begründungen, Bilder, Bräuche, Recht, Wiesbaden 1999 (Imagines Medii aevi, 3), S. 93-138, S. 98.

${ }^{69}$ Zur Definition vgl. Rüdiger SchNelL, Frauendiskurs, Männerdiskurs, Ehediskurs. Textsorten und Geschlechterkonzepte in Mittelalter und Früher Neuzeit, Frankfurt a.M. 1998 (Geschichte und Geschlechter, 23), S. 29. 


\section{Bestrebungen zur Fehdeeindämmung und gelehrtes Recht}

Aus Gründen der räumlichen Beschränkung kann die Ambivalenz der spätmittelalterlichen Landfrieden, die einerseits das Regelwerk der Fehde immer enger zogen und die andererseits nicht selten fürstliche Kriegsbündnisse begleiteten, hier nicht thematisiert werden ${ }^{70}$. Erwähnt sei nur, dass es bei der konstatierten Tendenz blieb, Fehden einzudämmen, aber nicht völlig zu verbieten. Sollten Verbote wirksam sein, musste erst einmal sichergestellt sein, dass der fehdeführende Adel überhaupt so weit in das Territorium eingebunden war, dass er an Vertragsabschlüsse der Fürsten gebunden war. Für Burgmannen, Amtleute und gesinde konnte das früher in Anspruch genommen werden als für jenen Adel, der Lehen in mehreren Territorien besaß. Insofern wurden fehdebeschränkende Bestimmungen nicht selten durch Artikel abgestützt, in denen Fürsten sich gegenseitig Hilfe gegen ihre eigenen Mannen oder die Mannen des Vertragspartners zusagten, falls diese sich nicht an die Vereinbarungen hielten, oder in denen sie dem Partner Nacheile ins eigene Territorium gestatteten ${ }^{71}$. In erster Linie waren es aber individuelle Verträge, gleich ob Sühnen oder Belehnungen, die den Adel den Schiedssprüchen und/oder Gerichtsurteilen des Lehnsherrn unterwarfen und über die Einbindung des Adels Friedensgrundlagen schufen. In diesem Zusammenhang taucht auch die Selbstverpflichtung auf, keine »unrechten Fehden « von den Lehnsobjekten aus zu führen, wobei Fehden dann »unrecht« waren, wenn man sich verpflichtet hatte, im Konfliktfall einen vom Herrn getätigten Ausgleich zu akzeptieren ${ }^{72}$. In einem solchen Fall war

70 Vgl. etwa Claudia GARNIER, Symbole der Konfliktführung im 14. Jahrhundert: Die Dortmunder Fehde von 1388/89, in: Westfälische Zeitschrift 151/152 (2001-2002, Druck 2002), S. 23-46, hier S. $27 \mathrm{f}$.

71 Vgl. Manfred Kaufmann, Fehde und Rechtshilfe. Die Verträge brandenburgischer Landesfürsten zur Bekämpfung des Raubrittertums im 15. und 16. Jahrhundert, Pfaffenweiler 1993 (Reihe Geschichtswissenschaften, 33), S. 20, 44-49 (mit brandenburgischen Beispielen). Bereits Gratian kannte den Gedanken, dass Krieg als Strafe gegen die geführt werden könne, die der eigenen Gerichtsbarkeit unterstünden.

72 ReINLE, Innovation (wie Anm. 35), S. 220f. mit Anm. 103. Zu den dort genannten Belegen können weitere beigefügt werden, vgl. StA Marburg, Urkunden 14, Nr. 10518 (Belehnung Hermann Riedesels mit dem Röhrenfurther Teil des Schlosses Ludwigseck, 1.4.1449); StA Marburg, Lehenbuch 3, fol. 146r-148r (Belehnung Hermann Riedesels mit dem Röhrenfurthschen Anteil von Schloss Ludwigseck vom 3.3.1459); StA Marburg, Kopiar 4, Nr. 388, fol. 105r-v, hier fol. 105v (Belehnung Hermann Harstalls mit einem Viertel des Schlosses Treffurt vom 25.10.1435), vgl. Regesten der Landgrafen von Hessen, Bd. 2: Regesten der landgräflichen Kopiare, 2 Teile, bearbeitet von Karl-Ernst DEMANDT, Marburg 1990 (Veröffentlichungen der Historischen Kommission für Hessen, 6/2), hier Nr. 762, S. 284, LandgrafenRegesten Online (wie Anm. 59), Nr. 2925 (Bearbeitungsstand des Regests vom 
der Herr seines Mannes nach der Sprache der Quellen »zu Recht mächtig«. Folgerichtig bezog im 15. Jahrhundert Gabriel Biel das fürstliche Fehdemonopol gegenüber Gerichtsunterworfenen, die »contumaces et rebelles« waren, auf die $»$ propriam iurisdictionem $«$ des princeps ${ }^{73}$.

Gänzlich wollte nur ein Landesherr während des Spätmittelalters die Fehde verbieten, nämlich Landgraf Friedrich der Ernsthafte von Thüringen 1338, der auf das Fehdeverbot gleich noch ein allgemeines Waffenverbot draufsetzte, von dem nur landgräfliche Amtsträger ausgenommen sein sollten $^{74}$. Obwohl dieser Landfriede nur für ein einziges Jahr erlassen wurde - von einer Verlängerung ist nichts bekannt - provozierte der Landgraf in der Folge mit der so genannten Grafenfehde 1342-1346 einen existentiell gefährlichen Aufstand des Thüringer Grafenadels ${ }^{75}$. Und auch die durchaus innovative Politik des Trierer Erzbischofs Balduin aus dem Hause Luxemburg, Fehden gegen seine Herrschaftsunterworfenen, etwa Städte oder Juden, als frevel bzw. excessus ahnden zu wollen ${ }^{76}$, fand unter seinem Nachfolger Werner von Falkenstein keine Fortsetzung ${ }^{77}$. In der Folge findet man wieder

22.6.2004); StA Marburg, Kopiar 4, Nr. 460, fol. 132r-134r (pfandweise Übertragung des Schlosses Ziegenberg an Georg v. Buttlar vom 22.2.1451), vgl. DEMANDT, Regesten 2.1, Nr. 834, S. 304, Landgrafen-Regesten Online Nr. 3036 (Bearbeitungsstand des Regests vom 23.6.2004).

73 Gabriel Biel, Collectorium (wie Anm. 31), Distinctio 15 qu. 4 art. 1 not. 1 C, S. 69. Zur iurisdictio, der »Gerichtsherrschaft«, die »Herrschaft über Personen schlechthin meinen konnte«, vgl. Jürgen MieTHKE, Politiktheorie im Mittelalter. Von Thomas von Aquin bis Wilhelm von Ockham. Durchgesehene und korrigierte Studienausgabe, Stuttgart 2008, S. 187.

${ }_{74}$ Andreas Ludwig Jakob MicheLSEN, Urkundlicher Beitrag zur Geschichte der Landfrieden in Deutschland. Eine archivalische Mittheilung, 1863, Nr. III, S. 23-26; Heinz ANGERMEIER, Königtum und Landfrieden im deutschen Spätmittelalter, München 1966, S. 141; Winfried LEIST, Landesherr und Landfrieden in Thüringen im Spätmittelalter 1247-1349, Köln 1975 (Mitteldeutsche Forschungen, 77), S. 159f.

75 Wilhelm FüsSLEIN, Die Thüringer Grafenfehde 1342-1346, in: Beiträge zur thüringischen und sächsischen Geschichte. Festschrift für Otto DOBENECKER zum 70. Geburtstag, Jena 1929, S. 111-138; Peter LANGHOF, Die Thüringer Grafenfehde und die Schwarzburger, in: Thüringen im Mittelalter. Die Schwarzburger, hg. vom Thüringer Landesmuseum Heidecksburg Rudolstadt, bearbeitet von Lutz UNBEHAUN, Rudolstadt 1995 (Beiträge zur schwarzburgischen Kunst- und Kulturgeschichte, 3), S. 131-145; Johannes MöTsCH, Die Thüringer Grafenfehde 1342 bis 1346, in: Hans HofFMEISTER, Volker WAHL (Hg.), Die Wettiner in Thüringen. Geschichte und Kultur in Deutschlands Mitte, Arnstadt 1999, S. 47-52; Gerd STRICKHAUSEN, Die Thüringer Grafenfehde und die Burgen Graf Günters XXI. von Schwarzburg (1326-† 1349), in: Christine MüLlER (Hg.), Burgenrenaissance im Historismus, München, Berlin 2007, S. 189-210.

76 Eulenstein, Territorialisierung (wie Anm. 26), Kap. 5.

${ }^{77}$ Freundlicher Hinweis von Dr. des. Julia Eulenstein (Gießen). 
keine allgemeinen landesherrlichen Fehdeverbote. Wenn die Kölner Erblandesvereinigung 1463 jedem Stiftsuntersassen verbot, einen anderen zu "veeden rouen brennen noch mit gewalt (zu) schedigen«, wenn er nicht vorher ein Gericht angerufen hatte, beinhaltet genau diese Bestimmung die Weitergeltung des subsidiären Fehderechts. Eine von Erzbischof Ruprecht von Köln wenige Wochen später abgeschlossene Erblandesvereinigung mit dem Kölner Domkapitel und den westfälischen Ständen folgte dieser Bestimmung ${ }^{78}$.

Auch die Reichsgewalt hatte weder den Ehrgeiz noch war sie in der Lage, ein allgemeines Fehdeverbot durchzusetzen. Erst seit der zweiten Hälfte des 15. Jahrhunderts summierten sich die befristeten Fehdeverbote allmählich zu Friedensperioden längerer Dauer ${ }^{79}$. Dagegen scheiterte 1438 ein kurfürstlicher Vorstoß, Fehden allgemein verbieten zu lassen, am Widerstand der Reichsstädte. Spät erst gelangte das römische Recht zur Geltung. Erstmals wurde 1424 die königliche Friedenswahrung unter den Schutz des Majestätsrechts gestellt und eine ihm entgegenstehende, mit mutwillen ausgeübte Fehdeführung verurteilt ${ }^{80}$. Seit der Mitte des 15. Jahrhunderts wurde die Idee, Fehdeführung ohne Erlaubnis des princeps sei ein Majestätsverbrechen, vernehmlicher vertreten; 1467 schließlich floss die Gleichsetzung von Landfriedensbruch mit Majestätsverbrechen in einen kaiserlichen Reichslandfrieden $e^{81}{ }^{81} . \mathrm{Zu}$ einem allgemeinen und unbefristeten Fehdeverbot kam es

78 Erblandesvereinigung der kurkölnischen Landstände, in: Theodor LACOMBLET (Hg.), Urkundenbuch für die Geschichte des Niederrheins, Bd. 4, Düsseldorf 1858, ND Aalen 1960, Nr. 325, S. 398-401, hier S. 400, Art. 17; Regina GöRNER, Raubritter. Untersuchungen zur Lage des spätmittelalterlichen Niederadels, besonders im südlichen Westfalen, Münster 1987 (Veröffentlichungen der Historischen Kommission für Westfalen, 22; Geschichtliche Arbeiten zur westfälischen Landesforschung, 18), S. 171 mit der weitergehenden Interpretation, es habe »bereits vor dem Ewigen Landfrieden von 1495 Versuche gegeben, die Fehde als Instrument der Rechtswahrung jedenfalls landesintern für unzulässig zu erklären«. Andere Territorien der Region wie das Hochstift Paderborn oder das Hochstift Münster setzten der adligen Fehdetradition keine Schranken.

79 Freundlicher Hinweis von Prof. Dr. Eberhard Isenmann (Köln).

80 Ernst SchuberT, König und Reich. Studien zur spätmittelalterlichen deutschen Verfassungsgeschichte, Göttingen 1979 (Veröffentlichungen des Max-Planck-Instituts für Geschichte, 63), S. 144 mit Anm. 182 mit Verweis auf: Deutsche Reichstagsakten (ältere Reihe), hg. durch die Historische Kommission bei der Bayerischen Akademie der Wissenschaften, Bd. 8: Deutsche Reichstagsakten unter Kaiser Sigmund, 2. Abt., 1421-1426, bearbeitet von Dietrich KerLER, Gotha 1883, Nr. 306, S. 363-365, hier S. 364.

$81 \mathrm{Zu}$ entsprechenden Äußerungen in der »Reformatio Sigismundi« und der »Concordantia Catholica« des Nikolaus von Kues vgl. SCHUBERT, König und Reich (wie Anm. 80), S. 144f., Anm. 183f. In der Folge werden die Belege zahlreicher, man 
trotzdem bekanntlich erst im Jahre 1495. Diese zeitliche Verzögerung muss nicht verwundern. Denn gelehrt-juristische Argumente schufen nicht automatisch breitere Akzeptanz für Änderungen im Bereich des jahrhundertealten Gewohnheitsrechts. Stattdessen musste eine langsame Bewusstseinsänderung folgen ${ }^{82} . \mathrm{Zu}$ dieser trug meines Erachtens jedoch die Popularisierung der kanonistischen Lehre durch die Medien der geistlichen Unterweisung (katechetische Literatur, Bußsummen, Rechtssummen und Beichtväterliteratur, aber auch Traktate) bei. Auch die Predigt dürfte eine - wenn auch schwer fassbare - Rolle gespielt haben ${ }^{83}$. Diesen von der englischsprachigen Forschung berücksichtigten ${ }^{84}$, in der deutschen Forschung aber lange vernach-

denke etwa an die Position des italienischen Rechtsgelehrten Martinus Garatus $(† 1453)$, vgl. ZIEGLER, Kriegsrechtliche Literatur (wie Anm. 9), S. 67; an ein einschlägiges Paduaner Rechtsgutachten, das die Reichsstadt Nürnberg ca. 1451/52 im Kontext der juristischen Bewertung des zweiten Städtekriegs einholte, vgl. IsENMANN, Reichsrecht und Reichsverfassung (wie Anm. 7), S. 606f.; an die Position der kaiserlichen Anwälte auf dem Regensburger Reichstag 1454, vgl. Ingeborg MosT, Der Reichslandfriede vom 20. August 1467. Zur Geschichte des Crimen laesae maiestatis und der Reichsreform unter Kaiser Friedrich III., in: Syntagma Friburgense. Historische Studien Hermann Aubin dargebracht zum 70. Geburtstag, Lindau, Konstanz 1956, S. 191-233, hier S. 206-208, 212 sowie - teils kritisch, teils ergänzend - SCHUBERT, König und Reich (wie Anm. 80), S. 145, Anm. 185; sowie an den Reichslandfrieden von 1467 vgl. Most, Der Reichslandfriede, S. 203-220; SCHUBERT, König und Reich, S. 145 und IsenManN, Reichsrecht und Reichsverfassung (wie Anm. 7), S. 604.

82 Anders argumentiert am dänischen Fallbeispiel Büchert Netterstrøm. Er schreibt ökonomischen Faktoren einen maßgeblichen Einfluss bei der Beendigung der dänischen Fehdepraxis zu, vgl. Jeppe BÜCHERT NetTeRstrøM, Feud in Late Medieval and Early Modern Denmark, in: Feud (wie Anm. 1), S. 175-187, hier S. 186.

${ }^{83}$ Dies mag man aus einer Geschichte schließen, die sich am Stuttgarter Hof zugetragen haben soll. Dort soll ein Barfüßermönch in einer Predigt vor dem Herzog und seinem Gefolge die Frage berührt haben, wie mit (adligen) Straßenräubern umzugehen sei, und sich zum Missfallen des Adels für eine harte Bestrafung ausgesprochen haben, vgl. Die Chronik der Grafen von Zimmern. Handschriften 580 und 581 der Fürstlich Fürstenbergischen Hofbibliothek Donaueschingen, hg. von Hansmartin DeCKer-HaufF, Bd. 2, Konstanz, Stuttgart 1967, S. 185. Auf eine weitere Predigt zu Krieg und Frieden wies Kümper hin, vgl. Hiram KüMPER, Der gerechte Krieg vor der Haustür. Die Legitimation von Fehdehandlungen in einer Bußschrift des 15. Jahrhunderts, in: Zeitschrift für Geschichtswissenschaft 56 (2008), S. 987-1004, hier S. 999, Anhang Nr. 3, S. 1003 f.

${ }^{84} \mathrm{Zu} \mathrm{Bußsummen} \mathrm{und} \mathrm{anderen} \mathrm{theologisch-kirchenrechtlichen} \mathrm{Textgattungen} \mathrm{vgl.} \mathrm{die}$ Ausführungen von BALDwIN, Masters, Princes and Merchants (wie Anm. 11), S. 206224; HyAms, Rancor and Reconciliation (wie Anm. 11), S. 43-59. Hyams untersucht geistliche Autoren, bes. Thomas of Chobham, die sich bei ihren Erörterungen zu den Todsünden des Hasses, des Neides und des Zorns mit der zeitgenössischen Rachekultur kritisch auseinandersetzten und diese verwarfen. 
lässigten Textgattungen sollen die abschließenden Ausführungen gelten. Übergangen werden muss ein ständedidaktischer Text, der »Ritterspiegel« des Erfurter Geistlichen Johannes Rothe (1414/vor 1418), der nach Pamela Kalnings Forschungen ebenfalls stark auf den Lehren vom gerechten Krieg basierte ${ }^{85}$.

\section{Katechese und popularisierende Rezeption des Kirchenrechts}

Katechesen und Rechtssummen folgten einem unterschiedlichen Aufbau und unterschiedlichen Argumentationslinien, kamen aber zu analogen Ergebnissen. Bereits ein fälschlich Thomas von Aquin zugeschriebener, ggf. von Wilhelm Peraldus $(\dagger 1271)$ verfasster Fürstenspiegel warnte Fürsten und Kriegsleute nachdrücklich vor der Liebe zu eitlem Ruhm (amor vanae gloriae) und Zorn (ira), mahnte zum Racheverzicht und stellte die Todsünde des Hasses als Folge von Krieg bzw. Fehde (guerra) mahnend in den Raum ${ }^{86}$. Auch müsse bedacht werden, dass mancher, der im Krieg sterbe, zugleich den ewigen Tod erleide - ein Übel, das, so der Verfasser, »durch nichts wieder gut gemacht werden kann $\ll^{87}$. Raub, Diebstahl und Brandstiftung werden als das einfache Volk schädigende Kriegsfolgen kritisiert ${ }^{88}$. Ohnehin solle zwischen

85 Pamela KALNING, Kriegslehren in deutschsprachigen Texten um 1400. Seffner, Rothe, Wittenwiler, Münster 2006 (Studien und Texte zum Mittelalter und zur frühen Neuzeit, 9), S. 89 zu den Datierungsversuchen der Forschung, sowie S. 126-134 zur Rückbindung an die Lehre vom gerechten Krieg.

${ }^{86}$ Guilelmus Peraldus, De eruditione principum, in: S. Thomae Aquinatis Opera Omnia ut sunt in indice thomisti coadditis 61 scriptis ex aliis medii aevi auctoribus curante Roberto BuSA, Bd. 7: Aliorum medii aevi auctorum scripta, 61, Stuttgart, Bad Cannstatt 1980, S. 89-121, hier 1b. 7, cap. 4-12, S. 120f. Eine durch Auslassungen wie durch neu geschaffene Übergänge gekennzeichnete und demnach sehr freie Übersetzung bietet Wilhelm Emanuel vON KeTteler (Hg.), H[einrich] BonE (Übers.), Über die Pflichten des Adels. Eine Stimme aus den Tagen des hl. Thomas von Aquin, Mainz 1868, Buch 7, Kap. 5-10, S. 462-482 (sowie S. XVII zu den Übersetzungsprinzipien). Die Übersetzung eignet sich trotz dieser Einschränkungen für eine erste Orientierung.

87 »et frequenter qui in bello moriuntur, morte aeterna moriuntur, quod est irremediabile malum «, vgl. Guilelmus Peraldus, De eruditione principum (wie Anm. 86), lb. 7, cap. 8, S. 120; Ketteler, Bone, Über die Pflichten des Adels (wie Anm. 86), Buch 7, Kap. 7.5, S. 473 (hier das im Obertext wiedergegebene Zitat).

88 »sequuntur inde incendia, rapinae et furta «, vgl. Guilelmus Peraldus, De eruditione principum (wie Anm. 86), lb. 7, cap. 8, S. 120; KeTteler, Bone, Über die Pflichten des Adels (wie Anm. 86), Buch 7, Kap. 7.5, S. 473. 
Christen kein Krieg bzw. keine Fehde (guerra) herrschen ${ }^{89}$ ! Besonders scharf verurteilte der Verfasser die Brandstiftung, die - als eigenmächtiges, d.h. unautorisiertes Brandlegen in böser Absicht definiert - ein Frevel vor Gott sei, dem die Nächstenliebe und die Gastfreundschaft besonders teuer seien. Sie sei teuflisch, und da der Brandstifter dem Teufel in seinem Tun ähnle, ereile ihn auch die Qual des Feuers. Doch auch als Sünde gegen den Heiligen Geist sei Brandstiftung zu betrachten, da sie ein »peccatum malitae purae sine aliqua utilitate « darstelle ${ }^{90}$. Schließlich bringe sie dem Opfer wie dem zum Schadensersatz verpflichteten Urheber Schaden und ziehe Letzterem womöglich eine von Gott erhörte Verfluchung seitens des Opfers zu. Zu guter Letzt seien irdische und himmlische Strafen der Lohn des Brandstifters ${ }^{91}$. Doch auch vor der Tötung von Menschen warnte der Verfasser, freilich »salva utilitate rei publicae«, worunter wohl der Vollzug der Todesstrafe und vermutlich auch die Beteiligung an einem gerechten Krieg gemeint waren ${ }^{92}$ Doch räumte er den Mahnungen vor dem Töten viel größeren Raum ein als dem Hinweis auf gerechtfertigtes Töten, so dass seine Skepsis unüberhörbar im

${ }^{89}$ Guilelmus Peraldus, De eruditione principum (wie Anm. 86), lb. 7, cap. 8, S. 121; Ketteler, Bone, Über die Pflichten des Adels (wie Anm. 86), Buch 7, Kap. 7.7, S. 474.

${ }^{90}$ Guilelmus Peraldus, De eruditione principum (wie Anm. 86), lb. 7, cap. 10, S. 121; KetTeler, Bone, Über die Pflichten des Adels (wie Anm. 86), Buch 7, Kap. 9.1-9.2, S. 477f. Zur Brandstifterdefinition, nach der ein incendiarius der sei, der »auctoritate propria [...] malo studio, sive pro odio sive pro vindicta e einen Brand lege, während der nicht Brandstifter im strafrechtlichen Sinn genannt werde, der »iussu eius qui habet potestatem indicendi bellum « handele, vgl. auch Georg STEER u.a. (Hg.), Die »Rechtssumme« Bruder Bertholds. Eine deutsche abecedarische Bearbeitung der "Summa Confessorum« des Johannes von Freiburg, 7 Bde., Tübingen 1987-1991, Bd. 6, B 33, S. 97.

${ }^{91}$ Guilelmus Peraldus, De eruditione principum (wie Anm. 86), lb. 7, cap. 10, S. 121; Ketteler, Bone, Über die Pflichten des Adels (wie Anm. 86), Buch 7, Kap. 9.2, S. $478 f$.

92 Guilelmus Peraldus, De eruditione principum (wie Anm. 86), lb. 7, cap. 11, S. 121; die oben vorgetragene Interpretation der Ausnahmeregelung findet sich auch bei Ketteler, Bone, Über die Pflichten des Adels (wie Anm. 86), Buch 7, Kap. 10, S. 479, Kap. 10.1, S. 479. Zur weiteren Argumentation a.a.O., S. 479-482. Eine ähnlich restriktive Haltung gegenüber dem Töten, das unbedingt zu vermeiden sei, nahm Gabriel Biel ein. Er wandte ein: »Cavendum tamen est in omni studio quantum fieri potest a caedibus hominum, ut non (nisi defensionis sui et aliorum aut rerum necessitas compellat) occidantur. Tanto siquidem gravius est iniuste bellantes occidere (dummodo commode et sine notabili damno salvari possunt), quanto tales sunt in maiori animae suae periculo, puta in actuali peccato iniuste bellando. Non enim tantum eorum corpora prosternuntur, sed etiam animae in mortem perpetuam transmittuntur«, vgl. Gabriel Biel, Collectorium (wie Anm. 31), Distinctio 15 Qu. 4 art. 2 conclusio 4, S. $74 f$. 
Vordergrund steht. Die gängigen Fehdepraktiken, so wird man subsummieren dürfen, stellten für den Verfasser buß- und beichtrelevante Vergehen dar.

\section{Heinrich von Langenstein und Stephan von Landskron}

Der Argumentation des Pseudo-Thomas folgte der an den Universitäten Paris und Wien lehrende Theologe Heinrich von Langenstein $(\dagger 1397)$ in seinem katechetischen Werk »Erchantnuzz der Sund « ${ }^{93}$. Heinrich ging an zwei Stellen auf die Problematik von Krieg und Fehde ein: zum einen bei der Abhandlung von Buße und Beichte ${ }^{94}$, zum anderen bei der Behandlung der sieben Todsünden, näherhin bei der Besprechung der Sünde des Zorns. Während Heinrich an der erstgenannten Stelle grundloses Kriegführen als Sünde bezeichnete, beklagte er im zweiten genannten Argumentationszusammenhang, welche Sünden vom Zorne kämen, nämlich »chrieg vnd werren«. Damit aber nicht genug, denn »Von werren chumpt chrieg, prennen, todsleg, rauben vnd anderlaÿ manikualtig svnd $\aleph^{95}$. Unter anderem sollte sich der Mensch deswegen vor Fehde und Krieg hüten, »wann an chriegen verdent dÿ vnschuldigen aller maist gelaidigt vnd verderbt, dÿ das nÿe verdient noch verwůrcht habent ${ }^{96}[\ldots]$ Dabei seien die wůtreich erger wenn der po̊s geist; wan er tüt niemant nichcz, wenn allain dem, der es verdient ${ }^{97}$. [...] An chriegen verderbt man auch arm lewt, den ir verderben gar schedleich ist; wann man tüt ainem weib grözzern schaden, das man ïr ain huen nimpt, wann ob man gar ainem reichen tausend mark nêm « ${ }^{98}$. Noch stärker als Raub und

${ }_{93}$ Heinrich von Langenstein, Erchantnuzz der sund. Nach österreichischen Handschriften, hg. von Rainer RudOLF, Berlin 1969 (Texte des späten Mittelalters und der frühen Neuzeit, 22), hier S. 21f. zur Abhängigkeit von der »Summa de vitiis et virtutibus« des Peraldus. Auf den Fürstenspiegel des Pseudo-Thomas/Peraldus verweist Rudolf nicht.

${ }_{94}$ Heinrich von Langenstein, Erchantnuzz der sund (wie Anm. 93), 1. Teil, Kap. 16: »Wem ein fürst peichten schol«. Erste, hier erweiterte Ausführungen zum folgenden Thema bereits in: Christine ReInLE, Umkämpfter Friede. Politischer Gestaltungswille und geistlicher Normenhorizont bei der Fehdebekämpfung im deutschen Spätmittelalter, in: Stefan ESDERS, Christine REINLE (Hg.), Rechtsveränderung im politischen und sozialen Kontext mittelalterlicher Rechtsvielfalt, Münster 2005 (Neue Aspekte der europäischen Mittelalterforschung, 5), S. 147-174, hier S. 163-168; zu Heinrich von Langenstein, vgl. ibid., S. $165 f$.

${ }_{95}$ Heinrich von Langenstein, Erchantnuzz der sund (wie Anm. 93), S. 193.

96 Ibid., S. 195.

${ }^{97}$ Ibid., S. 195.

98 Ibid., S. 195; dieselbe Argumentation findet sich auch bei Peraldus, De eruditione principum (wie Anm. 86), lb. 7, cap. 8, S. 120; KetTeler, Bone, Über die Pflichten des Adels (wie Anm. 86), Buch 7, Kap. 7.5, S. 473. 
Stehlen verdammte Heinrich, wie bereits Pseudo-Thomas vor ihm, das prennen, das er als ausschließlich destruktiv und zudem als feige empfand ${ }^{99}$. Wer Brände lege - eine übliche Fehdepraxis -, auf den warte das ewige Feuer ${ }^{100}$.

Stephan von Landskron wiederum, der 1477 verstorbene Propst von St. Dorothea in Wien, fand in einem weit verbreiteten katechetischen Werk, der »Himmelsstrasz«, bei der Erörterung der Todsünden und anlässlich der Zehn Gebote Gelegenheit, sich zu Fragen des Kriegführens, aber auch der Rache, zu äußern. Dabei führte er aus, dass Zorn eine Todsünde sei, wenn er den Menschen dazu bewege, sich selbst zu rächen oder gerächt werden zu wollen, ferner wenn er ihn dazu veranlasse, Rache vnrechtlich (zu Unrecht), on recht (wohl: ohne rechtliches Verfahren) oder wider recht (entgegen den Rechtsnormen) zu wünschen. Auch sei es nicht statthaft, Rache an jemandem zu üben, der keine Schuld trage, sich über das hinaus zu rächen, was jemand verschuldet habe oder sich an jemandem zu rächen, über den man keine »gewalt $[. .$.$] noch beuelchnus von dem der do gewalt hat «, habe: Wer nicht$ Oberer, Richter oder Schulmeister (!) sei, habe keine derartige Befugnis. Desgleichen dürfe man nicht danach verlangen, von jemandem gerächt zu werden, der dazu ebenfalls nicht die Vollmacht habe. Rache schließlich, die nicht dem Nutzen des Bestraften oder der Gerechtigkeit diene, sei ebenfalls nicht erlaubt ${ }^{101}$. Nächst dem Zorn stand die geytigkeyt im Verdacht, Gewalt hervorzubringen und zu gewaltsamer und widerrechtlicher Wegnahme von Gütern zu führen ${ }^{102}$.

Über die Reflexion der Todsünden und ihrer Folgen hinaus gab die Erörterung des Siebten Gebots dem Propst von St. Dorothea die Gelegenheit zu erläutern, dass die, die unrechte Kriege führten, ebenso wie ihre Helfer, Ratgeber, Unterkunftsgewährer und Beschirmer sündigten. Unrecht handelten die, die ohne Auftrag, Vollmacht oder Erlaubnis eines lantfürsten absagten und Land und Leute angriffen, raubten, (Menschen) fingen, töteten und Geld erpressten. Auch wenn diese sich einbildeten, durch ihre Absage entschuldigt zu sein, seien sie es doch nicht vor Gott. Nach Stephans Ansicht waren die

99 Heinrich von Langenstein, Erchantnuzz der sund (wie Anm. 93), S. 196.

100 Ibid., S. 197.

101 Stephan von Landskron, Die Hymelstrasz. Mit einer Einleitung und vergleichenden Betrachtungen zum Sprachgebrauch in den Frühdrucken (Augsburg 1484, 1501 und 1510) von Gerardus Johannes JASPERS, Amsterdam 1979 (Quellen und Forschungen zur Erbauungsliteratur des späten Mittelalters und der frühen Neuzeit, 13), fol. CIIIIr. Bei den Überlegungen Stephans könnten die auf Gratian zurückgehenden kanonistischen Überlegungen zur »uindicta« Pate gestanden haben, die - als Strafe verstanden - in kriegerischer Form erfolgen konnte, falls der zu Strafende der eigenen Gerichtsbarkeit unterstand, vgl. HeHL, Kirche und Krieg (wie Anm. 6), S.71f., $197 f$. 102 Ibid., fol. CXr. 
Täter zur Rückgabe des von ihnen oder mit ihrer Hilfe Geraubten verpflichtet. Schuldig waren jedoch auch jene, die den unrecht Fehdenden wehren könnten und dies nicht täten, etwa die landsherren vnd landsfürsten. Damit aber nicht genug: Auch in gerechten Kriegen dürfe man den Unschuldigen Ihre Habe nit vnrechtlich nehmen ${ }^{103}$. Wer sich also an die Mahnungen Stephans von Landskron hielt, konnte bereits unter dem Aspekt der Sünde kaum mehr noch zur rächenden Selbsthilfe greifen. Darüber hinaus wurde das Problem der Rache- und Fehdelegitimation im Sinne der auctoritas principis und der Amtsgewalt von Stephan von Landskron vermittelt.

Doch auch für die Helfer oder Anstifter von Fehdeführern hatte Stephan von Landskron wichtige Lehren parat. Ihre Gefährdung behandelte er unter dem Stichwort der frembden sünden, jener Sünden, die man nicht selbst beging, wohl aber veranlasste, verursachte oder billigte und für die man sich ebenfalls vor Gott zu rechtfertigen hatte. Wenn ein Herr seinem Knecht befehle zu rauben und zu stehlen, falle diese Sünde nicht nur auf den Knecht als den ausführenden Täter, sondern gleichermaßen auf den Herrn zurück ${ }^{104}$. Dieser versündigte sich sogar an zwei Seelen, nämlich der des Täters und der eigenen. Hinzukommen konnte noch die Verantwortung für all jene, die sich ihrerseits zu Rache für den Geschädigten aufgerufen fühlten und die nun ihrerseits absagten, raubten, fingen, Brände legten und mordeten. Auch deren Todsünden wurden dem ursprünglichen Verursacher vor Gott angelastet ${ }^{105}$. Aber nicht nur der, der ein Gebot erteilte, sondern auch der, der einen Gott oder der Gerechtigkeit zuwiderlaufenden Auftrag ausführte, sei es Knecht, Diener oder Untertan, machte sich schuldig ${ }^{106}$. Gleiches galt, wer zur Sünde riet, ihr zustimmte oder den Sünder lobte, um ihm zu gefallen ${ }^{107}$. Angesprochen fühlen sollten sich die, die in ihrem Land oder ihren Städten, Dörfern und Häusern duldeten, dass Land oder Leute geschädigt würden ${ }^{108}$, die einen Räuber lobten, »er seye ein rechter geselle vnnd kůejager er thürr den bawren wol kủe nemen oder sy vahen oder vmb die meüler schlahen oder sy laichen ${ }^{109}$, und insbesondere die, die Räubern und Übeltätern Zuflucht, Herberge und andere Hilfe gewährten und es ihnen ermöglichten, das gestohlene oder geraubte Gut zu behalten ${ }^{110}$, ja selbst Familienangehörige, die den Gewalttätern zu essen und trinken brächten oder die das fremde Gut

103 Ibid., fol. LXXIIv, LXXIIIr; vgl. auch fol. CXXXVr.

104 Ibid., fol. CXXVr.

105 Ibid., fol. CXXVr.

106 Ibid., fol. CXXVIv.

107 Ibid., fol. CXXVIIr-CXXXr.

108 Ibid., fol. CXXIXv.

109 Ibid., fol. CXXXv.

110 Ibid., fol. CXXXIr. 
nutzten ${ }^{111}$. Als Ausfluss ihrer Schuld waren sie alle wie die Täter selbst zum Schadensersatz gegenüber den Opfern verpflichtet, und diese Restitutionspflicht schloss auch ihre Nachkommen ein ${ }^{112}$. Weiterhin wurden jene auf ihre Schuld hingewiesen, die durch ihr Schweigen unrechte Taten ermöglichten oder die ihnen keinen Widerstand entgegensetzten, vor allem wenn sie aufgrund ihres Standes oder Amtes Schaden hätten abwehren müssen, wie dies für die »lantsfürsten vnd ander herren vnd amptleüt« galt. Selbst die Familienangehörigen, Diener und Räte, welche vom Schadentrachten der Herren und Amtleute wüssten und dies verschwiegen, wurden in die Pflicht genommen ${ }^{113}$.

Doch begnügte sich der Wiener Theologe nicht damit, auf die Sündhaftigkeit aller soeben genannten Handlungen hinzuweisen. Vielmehr bot ihm der Gedanke der Restitutionspflicht, der jeder Übeltäter, Helfer oder Begünstiger unterlag und die sich nicht nur auf noch vorhandenes, sondern auch auf verwüstetes und zerstörtes Gut samt den Folgekosten, etwa benötigten Krediten der Geschädigten, bezog, einen Hebel, um die Folgen der Sünde drastisch auszumalen ${ }^{114}$. Ersetzt werden musste, was man selbst geraubt hatte oder was von der Gruppe geraubt worden war, der man angehörte. Ohne Restitution (oder Verzicht des Geschädigten) keine Gewährung des Bußsakraments! Ersatz leisten musste auch der, der finanziell dazu nicht in der Lage war, falls die Geschädigten ihm nicht freiwillig und ohne Zwang verziehen. Im schlimmsten Fall sollte er alle seine Habe hergeben, mit Weib und Kind betteln gehen oder sonst »mit hertter arbeÿt« sein Brot verdienen. Erzwungener Verzicht auf Schadensersatz, wie dies für gewöhnlich landesherrliche Friedensverträge wechselseitig ihren Untertanen abverlangten, entpflichtete die krieger nicht in geistlicher Beziehung, und selbst eine Beichte in Rom war nichts nütze, wenn man das unrecht gewonnene Gut nicht zurückgab ${ }^{115}$. Erst recht waren in puncto Restitution zögerliche Übeltäter auf dem Totenbett zu mahnen. Gerade bei Edelleuten, Hofleuten, Räubern, Brandstiftern und ihresgleichen stand nach Stephan von Landskrons Ansicht zu befürchteten, dass sie noch auf dem Totenbett eine Wiedergutmachung mit dem Argument ablehnten, ihnen und ihren Kindern bliebe nichts, wenn sie Schadensersatz leisteten. Diese Verstockten sollten jedoch mit dem Hinweis auf die Gefährdung nicht nur des eigenen Seelenheils, sondern auch des ihrer Kinder, der Erben unrechten Guts bzw. fortdauernder Entschädigungsverpflichtungen, zur Einsicht gebracht werden ${ }^{116}$. Sowohl in

111 Ibid., fol. CXXXIIr.

112 Ibid., fol. CXXXVIr, CXXXVIIIv, vgl. auch fol. CCVIv.

113 Ibid., fol. CXXXIIv-CXXXIIIr (Zitat fol. XXXIIIr).

114 Ibid., fol. CXXXIIIIv-fol. CXXXVIIIv.

115 Ibid., fol. CXXXVIr.

116 Ibid., fol. CCVIIIv. 
geistlicher wie in weltlicher Beziehung waren die Folgen unrechter Fehde bzw. unrechten Krieges also für alle fatal, die auf irgendeiner Ebene involviert waren. Indem auch die Folgen für die Familien der Betroffenen drastisch vor Augen gestellt wurden, wird ersichtlich, welche Mühe Stephan von Landskron sich gab, fehdeförmliches Handeln mit zahlreichen Warntafeln zu umgeben.

\section{Bruder Berthold von Freiburg}

Während bei Stephan von Landskron das seelsorgerische Moment überwog, bot Bruder Berthold von Freiburg in seiner vielbenutzten »Rechtssumme«, einem schwer zu datierenden $»$ Bestseller ${ }^{117}$ des 14 . Jahrhunderts ${ }^{118}$, leicht recherchierbar Einblick in die kanonistische Kriegslehre. Denn Berthold bot in laientauglicher Weise anhand alphabetisch angeordneter Stichwörter ${ }^{119}$ gemäß den kanonistischen Lehren Auskunft darüber, wann Kriegführen eine Sünde war und wann nicht ${ }^{120}$. Darüber hinaus erörterte er, wer Krieg führen

117 So Uta StÖRmer-CAYSA, Gewissen und Buch im Mittelalter. Über den Weg eines Begriffes in die deutsche Literatur des Mittelalters, Berlin, New York 1998 (Quellen und Forschungen zur Literatur- und Kulturgeschichte, 14), S. 179 unter Berufung auf Kurt RUH, Versuch einer Begriffsbestimmung von »städtischer Literatur« im deutschen Spätmittelalter, in: Josef Fleckenstein, Karl Stackmann (Hg.), Über Bürger, Stadt und städtische Literatur im Spätmittelalter. Bericht über Kolloquien der Kommission zur Erforschung der Kultur des Spätmittelalters 1975-1977, Göttingen 1980 (Abhandlungen der Akademie der Wissenschaften in Göttingen. Phil-hist. K1. 3 F. 121), S. 311-328, hier S. 320.

118 Die Datierung des Texts schwankt. Derzeit plädiert Schnell, Frauendiskurs, Männerdiskurs, Ehediskurs (wie Anm. 69), S. 124 für eine Entstehung um 1360, während STÖRMER-CAYSA, Gewissen und Buch (wie Anm. 117), S. 179 das Werk auf die Zeit nach 1323 datiert.

119 Dazu StÖRmer-CAYSA, Gewissen und Buch (wie Anm. 117), S. 179.

120 SteER u.a. (Hg.), Die »Rechtssumme« Bruder Bertholds (wie Anm. 90), Bd. 3, K 49-51, S. 1484-1491. Ein Krieg war u.a. dann ohne Sünde, wenn er um geraubten Guts willen geführt wurde, die Wiederherstellung des Friedens im Lande bezweckte, wenn er nicht aus Hass und Rache sowie geitikhait bzw. girhait (also aus avaritia) geführt wurde, sondern um der Liebe, der Gerechtigkeit und des Gehorsams willen und wenn er die Bestrafung der Bösen sowie den Schutz der Guten bezweckte (ibid., K 50, S. 1486f.). Erlaubnis und Wissen dessen, der Gewalt über den Fehdewilligen hat, waren ebenfalls erforderlich. Die Bereitschaft des Herrn, das Unrecht zu strafen, delegitimierte kriegerische Handlungen des Geschädigten. Vor allen Kriegen musste Recht vor dem obristen herren geboten werden, vgl. a.a.O., K 50, S. 1488. Krieg führen könne außerdem ein Herr gegen seine Leute und ein Oberer gegen seinen Untertan, wenn dieser unrecht handelte, um ihn zu zwingen, recht zu handeln und das Unrecht wieder gutzumachen, vgl. a.a.O., K. 51, S. 1490f. Demnach betont Berthold 
dürfe - nämlich ein Oberer gegen seinen vndertan, wenn dieser wegen eines Unrechts bestraft werden müsse ${ }^{121}$, jedoch nicht »ein gemain mensch, der nicht ain herr ist, noch land vnd lawt vnder ym hat zebeschirmen «122. Auch die Frage, ob Untertanen an einem Krieg teilnehmen dürften, an dessen Rechtmäßigkeit sie zweifelten, wurde von ihm behandelt ${ }^{123}$. Die gleiche Frage griff, erneut ausgehend vom Problem der Restitution in Krieg oder Fehde geraubter Güter, ein situationsbezogener Traktat auf, der wohl ca. 1419/1420 in Utrecht geschrieben und von den dortigen Dominikanern geprüft sowie von weiterer Seite interpretierend ins Deutsche übersetzt wurde $^{124}$. Demnach mussten sich die Teilnehmer an einem bellum ihres Herrn darüber Rechenschaft ablegen, ob dessen Krieg/Fehde gerecht sei, denn nur in einem gerechten Krieg waren sie nicht schadensersatzpflichtig ${ }^{125}$. Auf Gehorsam berufen konnte sich ein subditus nur dann zu seiner Entlastung, wenn er sich über die Zulässigkeit des Krieges im Unklaren warr ${ }^{126}$. Schließ-

zum einen den Primat herrschaftlicher Rechtswahrung sowie den Subsidiaritätscharakter der Fehde, zum anderen erlaubt er den Einsatz militärischen Zwangs seitens des Herrn gegenüber dem Untergebenen. In Anbetracht der Uneindeutigkeit des Begriffs chrieg/krieg, der zunächst »Streit« im Sinne von »Rechtsstreit« bedeutete und dann auf ngewaltsam ausgetragenen Rechtsstreit« verengt wurde, können Bruder Bertholds Ausführungen auf Krieg und Fehde bezogen werden. Zur Begrifflichkeit vgl. JANSSEN, Art. »Krieg« (wie Anm. 28), S. 567f. sowie oben Anm. 26 und den Obertext zu dieser Anmerkung.

121 STEER u.a. (Hg.), Die »Rechtssumme« Bruder Bertholds (wie Anm. 90), Bd. 3, K 51, S. 1490. Zur Rechtsdurchsetzung gegenüber Untertanen vermittels eines Kriegs vgl. auch IsenMAnN, Recht, Verfassung und Politik (wie Anm. 7), S. 129.

122 SteER u.a. (Hg.), Die »Rechtssumme« Bruder Bertholds (wie Anm. 90), Bd. 1, B 33, S. 400. Bruder Berthold führt demnach die Berechtigung zur Kriegführung unter dem Stichwort der klassischen Kriegs- bzw. Fehdehandlung der Brandstiftung aus.

${ }^{123}$ SteER u.a. (Hg.), Die »Rechtssumme« Bruder Bertholds (wie Anm. 90), Bd. 3, K 53.

124 Hugo STEHKÄMPER, Ein Utrechter kanonistischer Traktat über Kriegsrecht (1419/1420), in: Zeitschrift der Savigny-Stiftung für Rechtsgeschichte, Kanonistische Abteilung 78 (1961), S. 196-265, hier S. 202, 206-208, 211-213, 237f., 244.

125 STEHKÄMPER, Traktat (wie Anm. 124), Art. F, S. 256; der lateinische Begriff bellum wird hier mit orloghe übersetzt. Stehkämper interpretierte den angeführten Passus dahingehend, dass Untertanen ihren Herrn in einem ungerechten Krieg nicht unterstützen dürften.

126 STEHKÄMPER, Traktat (wie Anm. 124), Art. F, S. 256f., vgl. auch S. 228f. Der Traktat argumentiert im Übrigen weniger prinzipiell und weniger moraltheologisch, als Stehkämpers z.T. forcierte Paraphrasen glauben machen. So wird die Klärung der Frage, ob ein Krieg gerecht sei, an Verhaltensregeln für konkrete Situationen zurückgebunden; diese fallen je nach Rechtmäßigkeit des Kriegs unterschiedlich aus. Eine solche Vorgehensweise setzt implizit die Prüfung der Rechtmäßigkeit des Kriegs durch die Beteiligten voraus, für welche auch die üblichen kanonistischen Kriterien benannt werden. Der Akt der Gewissenserforschung ist aber nicht Gegenstand des Traktats. 
lich sei noch auf eine Bußhandreichung sowie auf einschlägige »Summarien« hingewiesen, die »mit einiger Wahrscheinlichkeit« aus dem Kölner Kreuzbruderkonvent stammen und aus denen kürzlich Auszüge von Hiram Kümper publiziert wurden. Auch sie thematisierten das Problem des gerechten Krieges u.a. mit Hinblick auf die Entschädigungsproblematik ${ }^{127}$. Selbst Gabriel Biel subsummierte seine elaborierten Ausführungen über den gerechten Krieg unter die Frage: »Utrum in bello aquisita sint suis dominis restituenda « ${ }^{128}$.

Bei allen Autoren spielt die Frage der Motivation (etwa des Zorns) oder der Intention (etwa: sich rächen zu wollen) eine wichtige Rolle für die Bewertung der Handlungen. Die intentio recta, das subjektivste Moment der Kriegslehre, hatte damit einen zentralen Stellenwert. Darüber hinaus fanden Berthold, Stephan von Landskron und der Verfasser des Utrechter Traktats auch die Gelegenheit, die Frage der Autorisierung von Eigengewalt ${ }^{129}$ zu behandeln und damit das zweite Zentralkriterium eines gerechten Kriegs in den Blick zu nehmen. Noch weiter ging die Aufforderung an die Helfer in Krieg und Fehde, die Rechtmäßigkeit der gewaltsamen Auseinandersetzung, an der sie teilnahmen, zu überprüfen. Somit kann man feststellen, dass einerseits ethische Normen über geistliche Belehrung implementiert wurden und andererseits die Lehre vom gerechten Krieg Verbreitung fand.

\section{Heinrich von Gorkum}

Noch einen Schritt weiter ging Heinrich von Gorkum, denn er warf nicht fallbezogen, sondern grundsätzlich die Frage auf, ob die im römisch-deutschen Reich üblichen Fehden von der Lehre vom gerechten Krieg gedeckt seien. Den Anlass bot ihm die Analyse von Bürgerkriegskonstellationen in holländischen Städten, die immer wieder zur Vertreibung einer Parteiung durch eine andere führten und die damit das Problem der Eigenmacht, der Gegenwehr, des Beutemachens und der Restitution der Geschädigten bei Umkehr der Verhältnisse aufwarfen. Gerade weil Heinrich seine Stellungnahme entlang der Lehre vom gerechten Krieg entwickelte, kam er nicht umhin, diese Lehre mit der Rechtsgewohnheit der Fehde zu kontrastieren. Auch

127 KÜMPER, Der gerechte Krieg (wie Anm. 83), S. 998f. zur Provenienz der Texte.

S. 1002 zur Restitutionsproblematik.

128 Gabriel Biel, Collectorium (wie Anm. 31), q. 4, S. 65-67, hier S. 65.

129 STEHKÄMPER, Traktat (wie Anm. 124), Art. I, S. 25. Zur Frage, ob die auctoritas principis immer vonnöten war, um einen Krieg zu einem gerechten zu machen, existierten abweichende Aussagen. Im Verteidigungsfall sowie pro rebus repetendis war nach Innozenz III. und nach Raimund von Peñaforte die Erlaubnis des Fürsten nicht erforderlich, vgl. KeEn, Laws of War (wie Anm. 5), S. 67; Janssen, Krieg (wie Anm. 28), S. 573; vgl. ferner IsENMAnN, Recht, Verfassung und Politik (wie Anm. 7), S. 129. 
Heinrich nahm zuerst die Motivation der Fehdeführenden in den Blick, deren Lauterkeit er skeptisch beurteilte, schienen ihm doch Zorn, Racheverlangen und Lust, dem anderen Leid anzutun, zu obwalten. Doch auch die Autoritätsfrage stand einer Rechtfertigung derartiger Fehden im Wege: »Obgleich in manchen Gegenden eine alte Gewohnheit die Arten, Fehden zu führen, billigt«, schrieb Heinrich, »sehe ich dennoch in der Beichte nicht, dass diese durch Gott verständlich zu machen oder $\mathrm{zu}$ rechtfertigen sind «130. Und Heinrich fuhr fort: »Zum Beweis dieser propositio ist zu bemerken, dass eine alte Rechtsgewohnheit besonders im Reich erwachsen ist, dass nach vorangegangener Absage ein Herzog gegen einen Herzog oder Grafen oder umgekehrt und ebenso [diese] über andere Ritter oder Adlige, oder eine Stadt gegen eine Stadt oder gegen einen anderen Fürsten und umgekehrt Fehden erregen, indem sie Kriege führen und ihren Untergebenen viel Schaden zufügen, bis Vermittler eine akzeptierte Genugtuung erlangen, während sie erlaubtermaßen mit solchen Mitteln eine Durchsetzung ihrer Wünsche betreiben, wie die tägliche Not allzu sehr in ihrer Auswirkung bezeugt «131. Doch könnten Herren und Städte nicht ohne kaiserliche Erlaubnis Fehde führen, denn sie hätten den Kaiser über sich, an den sie sich bei Verletzung ihres Rechts wenden könnten. Dies gelte auch, wenn die Entfernung zum Reichsoberhaupt weit sei. Wenn vorgebracht werde, der Kaiser stimme all dem zu, weil er den Brauch kenne und ihm nicht widerspreche, sei dem entgegenzuhalten, dass die kaiserliche potestas vieles, was sie nicht verbessern könne, übergehe ${ }^{132}$. Nicht einmal Könige könnten sich der Fehde bedienen, denn über ihnen stehe noch immer einer: der Papst ${ }^{133}$. Interessant ist hierbei zweierlei: zum einen die konsequente Delegitimierung der Fehde unter Bezugnahme auf den princeps, zum anderen die Aushebelung des Gewohnheits-

${ }^{130}$ Heinrich von Gorkum, De iusto bello (wie Anm. 37), fol. 54vb-55ra: »Quamvis in pluribus locis antiqua consuetudo quosdam modos ducendi guerras approbet, non tamen in foro conscientie video ipsos aut entimandos aut iustificandos divinitus«; hierzu und zum Folgenden ReInLE, Innovation (wie Anm. 35), S. 216 mit Anm. 84.

${ }^{131}$ Heinrich von Gorkum, De iusto bello (wie Anm. 37), fol. 55ra: »Ad huius propositionis evidentiam est advertendum, quod antiqua consuetudo inolevit presertim in imperio quod previa diffidatione dux contra ducem vel comitem vel econverso et sic de aliis militaribus aut nobilibus aut civitas contra civitatem vel contra principem aliquem et econverso sibi invicem concitant guerras committendo bella et plurima damna suis subditis inferendo, quatinus adoptatam satisfactionem perveniant arbitrantes se ex talibus mediis licite suorum desideriorum exequutionem practicare, prout quotidiana tribulatio nimium testatur per effectum«.

132 Ibid., fol. $55 \mathrm{r}-\mathrm{v}$.

133 Ibid., fol. 55va-56ra; WeILER, Heinrich von Gorkum (wie Anm. 36), S. 281f. Der Gedanke, dass Könige, die keinen Oberherrn hätten, sich den Papst zum Richter nehmen sollten, wurde im Kontext der Kriegsproblematik bereits im Kreis um Petrus Cantor vertreten, vgl. BALDWIN, Masters, Princes (wie Anm. 11), S. 206. 
rechts ${ }^{134}$ dadurch, dass die in dessen Rahmen vorgebrachten Argumente einer Gewissensprüfung im Rahmen des Bußsakraments nicht standhielten.

Ich fasse zusammen: Nicht nur dem gerechten Krieg wurde im Reich Legitimität zugesprochen, sondern auch adliger Eigenmacht und ihrer Ausdrucksform, der Fehde. Faktisch erfolgte deren zunehmende Delegitimierung in den Territorien durch befristete fürstliche Friedensgebote. Ihnen vorgelagert war jedoch die Notwendigkeit, den Kreis derer auszuweiten, denen der Fürst zu gebieten hatte. Wechselt man aber die Perspektive und fragt man, warum die Begrenzung und zuletzt die Abschaffung der Fehde eine Chance hatte, akzeptiert zu werden, wird man stärker als auf die Gutachten der Juristen auf die Tätigkeit der Seelsorger und der Morallehrer - in einem weiteren, etwa auch Johannes Rothe umfassenden Sinn - verwiesen. Meines Erachtens spielten Didaxe, Katechese und Bußsakrament eine wichtige Rolle dafür, dass das in ganz anderen Verfassungsverhältnissen entwickelte Konstrukt des gerechten Krieges auch im Reich in breitere Schichten hineindiffundieren konnte. Die stark rechtshistorische Ausrichtung, die die Landfriedenforschung lange hatte und die es präferierte, rechtliche Verhältnisse allein aus rechtlichen Quellen abzuleiten, hat dafür lange Zeit den Blick versperrt. Die theologischen Diskurse, aber auch die allgemein-didaktischen Werke verdienen es jedoch, stärker als bisher in den Blick genommen zu werden.

134 Auch Stephan von Landskron ließ das Argument eines bestehenden Gewohnheitsrechts nicht gelten, wenn er es für moraltheologisch unvertretbar hielt, so im Hinblick auf das vermeintliche Recht, in der Fehde auch »Unschuldige« - also nicht Involvierte - zu schädigen. Nach Stephans Ansicht war »eine so̊liche gewonheÿte [...] mer ein schedliches verderben dann ein gewonheÿt«, vgl. Stephan von Landskron, Hymelstrasz (wie Anm. 101), fol. CXXXVv. Gedanklich stand Stephan von Landskron mit dieser Argumentation in einer ehrwürdigen Tradition: Bekanntlich hatte nicht erst Gregor VII. christliche Wahrheit gegen Rechtsgewohnheit mit der berühmten Formulierung ausgespielt: »Der Herr hat nicht gesagt: >Ich bin die Gewohnheit«, sondern: >Ich bin die Wahrheit««, vgl. die von Peter von Moos zusammengetragenen, auf Tertullian zurückgehenden Belege, dazu: Peter von Moos, Geschichte als Topik. Das rhetorische Exemplum von der Antike zur Neuzeit und die historiae im »Policraticus« Johanns von Salisbury (Ordo Bd. 2), Hildesheim u.a. 1988, hier S. 86. 


\section{Anhang I}

\section{Belege für »Selbsthilfevorbehalte«, insbesondere im hessischen Raum}

Vgl. eine erste Zusammenstellung von Belegen bei REINLE, Innovation (wie Anm. 35), S. 204f., dort Anm. 23, 25-26 S. 204f. Ergänzt werden können weitere Belege, so StA Marburg, Kopiar 4, Nr. 236, fol. 54v-55r, Bestellung Hermann Spiegels v. Desenberg zum hessischen Erbburgmann am 16.10.1372, vgl. auch DemandT, Regesten 2.1 (wie Anm. 72) Nr. 609, Nr. 241-242, Landgrafen-Regesten Online (wie Anm. 59) Nr. 1547 (Bearbeitungsstand des Regests: 26.5.2005); StA Marburg, Kopiar 4, Nr. 237, fol. 55r-v, Ernennung Johann Spiegels v. Desenberg und seiner Neffen am 16.10.1372 zu hessischen Erbburgmannen bis zur Rückzahlung von 60 Mark, vgl. DemandT, Regesten 2.1, Nr. 610, S. 242, Landgrafen-Regesten Online, Nr. 1548 (Bearbeitungsstand des Regests vom 26.5.2004); StA Marburg, Kopiar 4, Nr. 432, fol. 121v-122r, Belehnung mehrerer v. Bodenhausen mit Schloss Arnstein am 15.7.1434, vgl. DEMANDT, Regesten 2.1, Nr. 806, S. 296, Landgrafen-Regesten Online, Nr. 2965 (Bearbeitungsstand des Regests vom 22.6.2004) (die hier interessierende Passage fehlt im Regest).

Besonders deutlich wird der Selbsthilfevorbehalt in einer Urkunde vom 22.2.1443 ausgedrückt, die die Bedingungen enthielt, unter denen die Brüder v. Herda gegen ein Darlehen von $500 \mathrm{fl}$. Erbburgmannen des Landgrafen von Hessen wurden und den landgräflichen Anteil des Schlosses Barchfeld amtsweise erhielten. Zunächst wurde den v. Herda der Verzicht auf Verfolgung ihres Rechts vermittels der Fehde eingeschärft und festgelegt, dass der Landgraf ihrer zu Recht mächtig sein solle. Kamen sie jedoch nicht durch den Landgrafen zu ihrem Recht, »alsdan solten wir in gunnen ire recht gein die selbin von dem slosse Barchfelt zcu foerdern mit feheden adir sust wie sie kunden doch mit eren«, vgl. StA Marburg, Kopiar 4, Nr. 459, fol. 131r-132r, hier fol. 131v; DEMANDT, Regesten 2.1, Nr. 833, S. 404, LandgrafenRegesten Online Nr. 3035 (Bearbeitungsstand des Regests vom 23.6.2004) (Regest ohne die Wiedergabe der hier interessierenden Passage). Vgl. weiterhin Reinhard TIESBRUMMEL, Das Lehnrecht der Landgrafschaft Hessen (Niederhessen) im Spätmittelalter 1247-1471, Darmstadt, Marburg 1990 (Quellen und Forschungen zur hessischen Geschichte, 76), S. 154.

Weniger eindeutig auf die Berechtigung zur Fehdeführung zu verweisen scheinen mir die Regelungen in der Urfehde des Rudolf v. Helfenberg vom 18.4.1392, nach der dieser sich verpflichtete, dem Landgrafen von Hessen, seinen Erben, ihren Landen und Leuten und all denen, die vom Landgrafen zu Recht verantwortet würden, nicht mehr feindlich zu begegnen und sein Recht vor dem Landgrafen zu suchen. Könne der Landgraf ihm nicht zu seinem Recht verhelfen, durfte Helfenberg »ein recht an den erkobirn alse lange bijs mir von en rechts von en geholffen würde«, ohne gegen die Urfehde verstoßen zu haben (StA Marburg, Urkunden 8, Nr. 219). Hier kann auch die 
Hinwendung zu einem anderen Gericht als dem landgräflichen mit der Formulierung des »recht [...] erkobirn« gemeint sein. In gleicher Weise behielt sich am 18.4.1392 auch Hartrad v. Hunoldshausen vor, sich bei Rechtsverweigerung "ein recht an den erkobirn alse lange bijs mir von en rechts von en geholffen würde«, vgl. StA Marburg, Urkunden 8, Nr. 220. Zur übereinstimmenden Urkunde Heinrichs v. Hunoldshausen vom gleichen Tag vgl. StA Marburg, Urkunden 8, Nr. 221. Ohne Rekurs auf einen Selbsthilfevorbehalt ging die Kanzlei Landgraf Ludwigs I. davon aus, dass Eckhard Riedesel oder seine Erben das ihnen verpfändete Schloss Schotten ggf. »von ires kriges vnd fehide wegen « verlieren könne. Für diesen Fall wurden Bestimmungen getroffen, vgl. StA Marburg, Kopiar 4, Nr. 334, fol. 88r-89r, DeMANDT, Regesten 2.1, Nr. 708, S. 268f., Landgrafen-Regesten Online, Nr. 2874 (Bearbeitungsstand des Regests 19.3.2003). Eine gleichartige Bestimmung enthielt die Pfandschreibung an Georg v. Buttlar vom 22.2.1451, zu ihr s.u. Anm. 72. Die Fehdeführung eines Amtmanns von einem Amt aus war für den Landesherrn noch problematischer als die von einem Pfandobjekt aus; sie wurde daher geregelt, aber nicht immer verboten, vgl. GöRNER, Raubritter (wie Anm. 78) S. 134f.

\section{Anhang II \\ Belege für »Selbsthilfevorbehalte«, insbesondere im welfischen Gebotsbereich}

SUdENDORF, Urkundenbuch (wie Anm. 46), Bd. 3, Nr. 250, S. 163f., hier S. 163 (Revers des Burchard v. Marenholtz wegen der Verpfändung von Schloss und Gericht Bahrdorf vom 6.12.1364); a.a.O., Nr. 312, S. 207-209, hier S. 208 (Revers des Günzel v. Bertensleben und des Conrad v. Steinberg wegen Verpfändung von Schloss und Gericht Knesebeck am 7.3.1367); a.a.O., Nr. 369, S. 249f., hier S. 250 (Verpfändung eines Teils von Schloss Ambleben an Heinrich v. Oberg und Wilhelm v. Utze am 24.6.1368); a.a.O., Bd. 6, Nr. 25, S. 22f. (Revers des Hermann Bock über die Einsetzung auf Schloss Eldagsen vom 25.11.1382); a.a.O., Bd. 6, Nr. 130, S. 145f. (Sühne der Brüder Arnd und Hinrik v. Roringen mit Herzog Otto von Braunschweig vom 28.9.1385; die subsidiäre Selbsthilfeberechtigung schließt hier auch die Hilfe für Freunde der Aussteller ein); a.a.O., Bd. 7, Nr. 10, S. 10-14 (Unterstellung des Albrecht v. Alvensleben und des Rudolf v. Kloden unter den herzoglich-braunschweigischen Dienst und Schutz unter Einschluss der Öffnung ihres Schlosses Klötze am 13.3.1390); a.a.O., Bd. 7, Nr. 13, S. 15f., hier S. 15 (Versprechen Herzog Friedrichs von Braunschweig-Lüneburg vom 8.5.1390, die Ritter Aschwin und Johann v. Salder sowie Aschwin v. Salder bei ihren Rechten zu erhalten); a.a.O., Bd. 7, Nr. 14, S. 16-18, hier S. 17 
(Verpfändung von Schloss Lichtenberg an Mitglieder des Hauses v. Salder für die Dauer von sechs Jahren am 8.5.1390). Auch in der Landgrafschaft Hessen konnte sich die pfandweise Übernahme eines Schlosses mit dem Zugeständnis eines subsidiären Fehderechts vom Schlosse aus verbinden, wie eine Urkunde vom 25.10.1435 belegt, vgl. StA Marburg, Kopiar 4, Nr. 388, fol. 105rv; DemandT, Regesten 2.1 (wie Anm. 72) Nr. 762, S. 284. Selbsthilfevorbehalte finden sich auch bei Verpfändungen in Thüringen, vgl. z.B. Codex Diplomaticus Saxoniae Regiae. Erster Haupttheil. Abt. B. Bd. 1-3, hg. von Hubert ERMISCH, Leipzig 1899-1909, Bd. 1, Nr. 290, S. 227f., Nr. 296, S. 231f., Bd. 2, Nr. 463f., S. 309f., Bd. 3, Nr. 377, S. 320f. - Die Zahl der Belege ließe sich vermehren.

\section{Anhang III \\ »Selbsthilfevorbehalte« in Sühnelehen}

Hier verbindet sich die Sühne mit einer erzwungenen Lehnsnahme. Ein Beispiel für einen solchen Selbsthilfevorbehalt bietet die als Folge einer Fehde Erzbischof Balduins von Trier zustande gekommene Belehnung Jakobs v. Montclair im Jahre 1339, hierzu EulENSTEIN, Territorialisierung (wie Anm. 26), S. 343f. Als weiteres Beispiel können die Pflichten genannt werden, die der Edelherr Jakob v. Westerburg 1359 bzw. zwischen 1353 und 1367 im Zusammenhang mit einer Sühne und einer Auflassung eigenen Guts zu landgräflich-hessischem Lehen eingehen musste, vgl. StA Marburg, Kopiar 4, Nr. 145, fol. 41r, DemAndT, Regesten 2.1 (wie Anm. 72) Nr. 65, S. 89 und Nr. 571, S. 226, Landgrafen-Regesten Online (wie Anm. 59) Nr. 1264 (Bearbeitungsstand des Regests vom 11.5.2004), Nr. 1349 und Nr. 2740 (Bearbeitungsstand des Regests vom 17.05.2004). Johann v. Westerburg wurde bei Rechtsverweigerung sogar die Fehde gegen den Landgrafen gestattet. Hingewiesen sei ferner auf die Sühne des Ritters Simon v. Wallenstein und seiner Söhne mit Landgraf Otto vom 25.6.1357, die ebenfalls mit der Aufnahme einer Lehnsbeziehung verbunden werden sollte. Auch sie enthielt eine subsidiäre Selbsthilfeklausel, vgl. StA Marburg, Kopiar 4, fol. 99r-100r, hier fol. 99v, DEMANDT, Regesten 2.1, Nr. 751, S. 280f., Landgrafen-Regesten Online Nr. 1239 (Bearbeitungsstand des Regests vom 10.5.2004) (freilich ohne Hinweis auf die hier interessierende Bestimmung). 